\title{
Composites
}

\section{Effects of the core density on the quasi-static flexural and ballistic performance of fibre-composite skin/foam- core sandwich structures}

\author{
Cihan Kaboglu ${ }^{1}$, Long $\mathrm{Yu}^{1}$, Iman Mohagheghian ${ }^{2}$, Bamber R. K. Blackman ${ }^{1}$, Anthony J. Kinloch ${ }^{1, *}$, and \\ John P. Dear ${ }^{1, *}$ \\ ${ }^{1}$ Department of Mechanical Engineering, Imperial College London, South Kensington Campus, London SW7 2AZ, UK \\ ${ }^{2}$ Department of Mechanical Engineering Sciences, University of Surrey, Guildford, Surrey GU2 7XH, UK
}

Received: 1 June 2018

Accepted: 10 August 2018

Published online:

20 August 2018

(C) The Author(s) 2018

\begin{abstract}
Polymeric foams are extensively used as the core materials in sandwich structures and the core material is typically bonded between relatively thin fibrecomposite skins. Such sandwich structures are widely used in the aerospace, marine and wind-energy industries. In the present work, various sandwich structures have been manufactured using glass-fibre-reinforced polymer (GFRP) skins with three layers of poly(vinyl chloride) foam to form the core, with the densities of the foam layers ranging from 60 to $100 \mathrm{~kg} / \mathrm{m}^{3}$. This study has investigated the effects on the quasi-static flexural and high-velocity impact properties of the sandwich structures of: (a) the density of the polymeric-foam core used and (b) grading the density of the foam core through its thickness. The digital image correlation technique has been employed to quantitatively measure the values of the deformation, strain and onset of damage. Under quasistatic three-point and four-point bend flexural loading, the use of a low-density layer in a graded-density configuration reduced the likelihood of failure of the sandwich structure by a sudden force drop, when compared with the core configuration using a uniform (i.e. homogenous) density layer. The high-velocity impact tests were performed on the sandwich structures using a gas-gun facility with a compliant, high-density polyethylene projectile. From these impact experiments, the graded-density foam core with the relatively lowdensity layer located immediately behind the front (i.e. impacted) GFRP skin was found to absorb more impact energy and possess an increased penetration resistance than a homogeneous core structure.
\end{abstract}

Address correspondence to E-mail: a.kinloch@imperial.ac.uk; j.dear@imperial.ac.uk 


\section{Introduction}

There is an increasing interest in sandwich structures manufactured using a lightweight polymeric foam as the core material. These sandwich structures often have skin materials of thin sheets of a glass-fibre-reinforced-polymer (GFRP) or a carbon-fibre reinforced-polymer (CFRP) [1-4]. The GFRP or CFRP skins can experience surface damage, such as indentation, delamination and debonding [5-7]. However, with sufficiently thick skins and adequate adhesion between the core and the skins, these sandwich structures can exhibit a relatively high flexural stiffness and possess both a good strength-toweight ratio and good energy absorption capabilities [8]. The deformation and failure characteristics of the foam core play a very important role in determining the mechanical performance of the sandwich structure. Hence, many research studies [9-18] have explored new types of sandwich structures by changing the type and density of the material used for the core.

Steeves and Fleck [9, 10] performed three-point bend flexural tests on sandwich structures consisting of a poly(vinyl chloride) (PVC) foam core and woven GFRP skins. The effects of the density and the thickness of the PVC foam core on the flexural properties of the sandwich structures were studied in detail. Steeves and Fleck derived analytical expressions for the competing failure modes: shear cracking, core crushing (indentation), compressive microbuckling and wrinkling. Abbadi et al. [11] undertook four-point bend tests of sandwich structures with two different densities of aluminium foam and found that the density of the core material greatly influenced the failure mechanisms, with the high-density foam imparting the highest failure strength. Juntikka and Hallstrom [12] reported that the shear modulus, shear strength and shear strain at failure of sandwich structures were all affected by the choice of the density for the core material. Fathi et al. [13, 14] investigated the effect of the type of core material employed on the flexural properties of the sandwich structure for four different core materials made from PVC, poly(ethylene terephthalate) (PET), polyurethane (PU) and balsa wood, with skins of GFRP. All of these different types of sandwich structures were evaluated under four-point bend loading and it was found that the balsa-wood core imparted the highest shear strength. However, a very sudden and catastrophic failure of the sandwich structure manufactured using the balsa-wood core occurred, but at a relatively high force. Kaboglu et al. [15] have performed four-point bend tests, using Digital Image Correlation (DIC) techniques, to understand the effects of different core materials on the flexural behaviour of sandwich structures manufactured using cores of PET, 'Tycor' and balsa wood. ('Tycor' is a core that has glass fibre reinforcements through the thickness of a closed PU foam.) They found a balsa-wood core gave the highest flexural stiffness and strength compared to using the PET or 'Tycor' materials as the core. However, a PET core resulted in the best damage tolerance for the sandwich structure. Battley and Burman [16] have also investigated the effects of different types of core materials on the failure mechanisms under four-point bend flexural tests and concluded that the yield stress of the core material was a key parameter in controlling the failure mechanism of the sandwich structure.

Zhou et al. [19] studied the effect of the skin thickness, core densities and indenter shape on the impact behaviour and failure mechanisms of sandwich structures made of CFRP skins and a 'Nomex' honeycomb (i.e. an aramid-based paper) core material. They concluded that the nose shape of the indenter was the most significant test parameter that affected both the failure mechanism and energy absorption of the sandwich structure. They also found that the energy absorption of the sandwich structure was increased by increasing the skin thickness and the core density. Mines et al. [20] studied the impact behaviour of sandwich structures made of woven GFRP skins with different types of core materials. They concluded that the energy absorbing capacity of the sandwich structure increased with increasing loading rate and that this was due to strain-rate effects on the crushing of the core and the fracture of the skins.

Dear et al. [21, 22] investigated the impact behaviour of sandwich structures manufactured using two different skin materials (i.e. an aluminium alloy and a GFRP) and two different core materials (i.e. 'Nomex' and an aluminium honeycomb) under a low-velocity impact. They found that reducing the thickness of the core materials increased the damage area. Garcia-Castillo et al. [23] have performed highvelocity impact tests on sandwich structures manufactured from GFRP skins with PVC foam cores and 
found that the core properties controlled the failure mechanisms but had less effect on the ballistic limit, i.e. the velocity at which perforation of the skin(s) of the sandwich structure occurs. Razali et al. [24] also found that the core properties are of major importance in determining the impact failure mechanisms of a sandwich structure.

In the present paper, the focus is on examining the flexural and impact behaviour of sandwich structures manufactured with graded-density PVC foam cores with GFRP skins, as these types of sandwich structures have not been studied in detail. The main objectives are to identify the effect of the density variation through the thickness of the polymericfoam core on: (a) the deformation and strain responses of the sandwich structures from quasistatic three-point bend and four-point bend flexural tests, and high-velocity impact tests and (b) the failure mechanisms of the sandwich structures when subjected to such tests.

\section{The sandwich structures}

\section{The materials}

The sandwich structures investigated in the present study were manufactured using a cross-linked PVC closed-cell foam. These foam layers were supplied by AIREX AG, Switzerland, in three different densities. The properties $[25,26]$ of these various PVC foam materials are shown in Table 1 . The skins were a GFRP composite which was based upon a $+45^{\circ} /-45^{\circ}$ biaxial E-glass stitched fabric, which was 'XE603' from Gurit, UK, see Table 2. Three layers of the $\pm 45^{\circ}$ biaxial E-glass stitched fabric were stacked for each skin and a $\left(0^{\circ} / 90^{\circ} /-45^{\circ} /+45^{\circ} /\right.$ $90^{\circ} / 0^{\circ}$ ) lay-up was prepared by suitably rotating the fabric. The thickness of the GFRP skin was approximately $1.5 \mathrm{~mm}$. Three layers of 5-mm-thick PVC foam were stacked together to make the core, and a very thin layer of an epoxy adhesive was applied between the layers. The epoxy matrix resin ('Prime $\left.20 \mathrm{LV}^{\prime}\right)$ and the slow-curing hardener for the glass fabric were also both from Gurit, UK. The sandwich structures were made as panels, $680 \times 320 \mathrm{~mm}^{2}$ in size, using a Resin Infusion under Flexible Tool (RIFT) manufacturing method. The flow media, peel ply and vacuum bagging were put on top of the glass-fibre fabric/PVC core/glass-fibre fabric sandwich structure, and this assembly was then placed on the base plate of the tooling. The resin was then infused into the glass-fibre fabric under vacuum. (It should be noted that there was no adhesive layer between the core layers and the skins. Thus, the necessary adhesion between the core and the skins was achieved by the infusing liquid resin wetting and adhering to the upper- and bottom-most surfaces of the three layers of the PVC foam core.) The tooling temperature was maintained at $20{ }^{\circ} \mathrm{C}$ for $510 \mathrm{~min}$ to undertake the initial cure of the GFRP skins. The GFRP skins were then post-cured at $65{ }^{\circ} \mathrm{C}$ for 4 to $6 \mathrm{~h}$. The oven was then switched off and left to cool at a natural rate. For the three-point and four-point flexural bend specimens, the panels were cut into rectangular sections.

Table 1 Properties of the three different densities of the PVC foam core materials $[25,26]$

\begin{tabular}{lllll}
\hline & Units & Low density $<60>$ & Medium density $<80>$ & High density $<100>$ \\
\hline Density & $\left(\mathrm{kg} / \mathrm{m}^{3}\right)$ & 60 & 60 & 100 \\
Compressive modulus & $(\mathrm{MPa})$ & 69 & 104 & 130 \\
Compressive strength & $(\mathrm{MPa})$ & 0.90 & 1.45 & 2.0 \\
Compressive strain at yield & & 0.013 & 0.014 & 0.015 \\
Shear modulus & $(\mathrm{MPa})$ & 22 & 30 & 40 \\
Shear strength & $(\mathrm{MPa})$ & 0.85 & 1.2 & 1.7 \\
Shear strain at yield & & 0.039 & 0.040 & 0.043 \\
\hline
\end{tabular}

Table 2 The glass-fibre fabric employed for the GFRP skins

\begin{tabular}{lllll}
\hline Manufacturer & Reference & Style & Nominal $\left(\mathrm{g} / \mathrm{m}^{2}\right)$ & Primary fibre type \\
\hline Gurit, UK & 'XE603' & $+45 /-45$ biaxial fabric & 601 & E-glass \\
\hline
\end{tabular}


The configurations used for the core of the sandwich structures

Five different configurations for the three layers of the PVC foam core for the sandwich structures were designed and tested. The design criteria employed were: (a) to maintain a relatively high average density for the core (b) to keep the average density of the core always similar in value, and (c) to examine the ordering sequence for the three layers of the PVC foam that comprised the core. Sandwich structures with five different configurations of the PVC foam core, which met these criteria, were investigated, see also Table 3:

1. Uniform-density core with three layers of medium density foam: $<80: 80: 80>$;

2. Graded-density core with three layers of low/ high/low-density foam: <60:100:60>;

3. Graded-density core with three layers of high/ low/high-density foam: $<100: 60: 100>$;

4. Graded-density core with three layers of low/ medium/high-density foam: $<60: 80: 100>$;

5. Graded-density core with three layers of high/ medium/low-density foam: $<100: 80: 60>$.

\section{Experimental}

Firstly, quasi-static three-point and four-point bend tests were performed in accordance with ASTM C393 [27] in order to obtain information on the flexural behaviour of the sandwich structures. Secondly, the impact performance of the sandwich structures was assessed using a gas-gun facility (See Fig. 1). For the three-point and four-point bend tests, the dimensions of the specimen and the loading rollers are shown in Figs. 1a and b. It should be noted that for both types of flexural test, rubber pads were placed under the cylindrical loading rollers to avoid any localised damage to the GFRP. The rate of the cross-head displacement employed during the flexural tests was $6 \mathrm{~mm} / \mathrm{min}$.

A Digital Image Correlation (DIC) method was employed to map the resulting strains that developed in the specimen during the test. Images were taken every two seconds using an 'Aramis $5 \mathrm{M}^{\prime}$ camera, supplied by GOM, Germany, to create an image series. A 2D analysis was then undertaken using the 'Aramis' software, supplied by GOM, Germany. Only a 2D analysis was required since the deflection of the specimen was only in two directions. Nevertheless,

Table 3 Configurations of the PVC foam core used the sandwich structures

\begin{tabular}{|c|c|c|c|c|c|}
\hline Configuration & $<80: 80: 80>$ & $<60: 100: 60>$ & $<100: 60: 100>$ & $<60: 80: 100>$ & $<100: 80: 60>$ \\
\hline \multirow{5}{*}{$\begin{array}{c}\text { Foam density } \\
\qquad \& \\
\text { thickness }\end{array}$} & \multicolumn{5}{|c|}{6 layers of glass fibre (in 0/90/-45/+45/90/0 lay-up, total $1800 \mathrm{gsm}$ ) with epoxy matrix } \\
\hline & $80 \mathrm{~kg} / \mathrm{m}^{3}(5 \mathrm{~mm})$ & $60 \mathrm{~kg} / \mathrm{m}^{3}(5 \mathrm{~mm})$ & $100 \mathrm{~kg} / \mathrm{m}^{3}(5 \mathrm{~mm})$ & $60 \mathrm{~kg} / \mathrm{m}^{3}(5 \mathrm{~mm})$ & $100 \mathrm{~kg} / \mathrm{m}^{3}(5 \mathrm{~mm})$ \\
\hline & $80 \mathrm{~kg} / \mathrm{m}^{3}(5 \mathrm{~mm})$ & $100 \mathrm{~kg} / \mathrm{m}^{3}(5 \mathrm{~mm})$ & $60 \mathrm{~kg} / \mathrm{m}^{3}(5 \mathrm{~mm})$ & $80 \mathrm{~kg} / \mathrm{m}^{3}(5 \mathrm{~mm})$ & $80 \mathrm{~kg} / \mathrm{m}^{3}(5 \mathrm{~mm})$ \\
\hline & $80 \mathrm{~kg} / \mathrm{m}^{3}(5 \mathrm{~mm})$ & $60 \mathrm{~kg} / \mathrm{m}^{3}(5 \mathrm{~mm})$ & $100 \mathrm{~kg} / \mathrm{m}^{3}(5 \mathrm{~mm})$ & $100 \mathrm{~kg} / \mathrm{m}^{3}(5 \mathrm{~mm})$ & $60 \mathrm{~kg} / \mathrm{m}^{3}(5 \mathrm{~mm})$ \\
\hline & \multicolumn{5}{|c|}{6 layers of glass fibre (in 0/90/-45/+45/90/0 lay-up, total $1800 \mathrm{gsm}$ ) with epoxy matrix } \\
\hline $\begin{array}{c}\text { Average core } \\
\text { density }\end{array}$ & $80 \mathrm{~kg} / \mathrm{m}^{3}$ & $73 \mathrm{~kg} / \mathrm{m}^{3}$ & $87 \mathrm{~kg} / \mathrm{m}^{3}$ & $80 \mathrm{~kg} / \mathrm{m}^{3}$ & $80 \mathrm{~kg} / \mathrm{m}^{3}$ \\
\hline Symbol used & & & & & \\
\hline
\end{tabular}



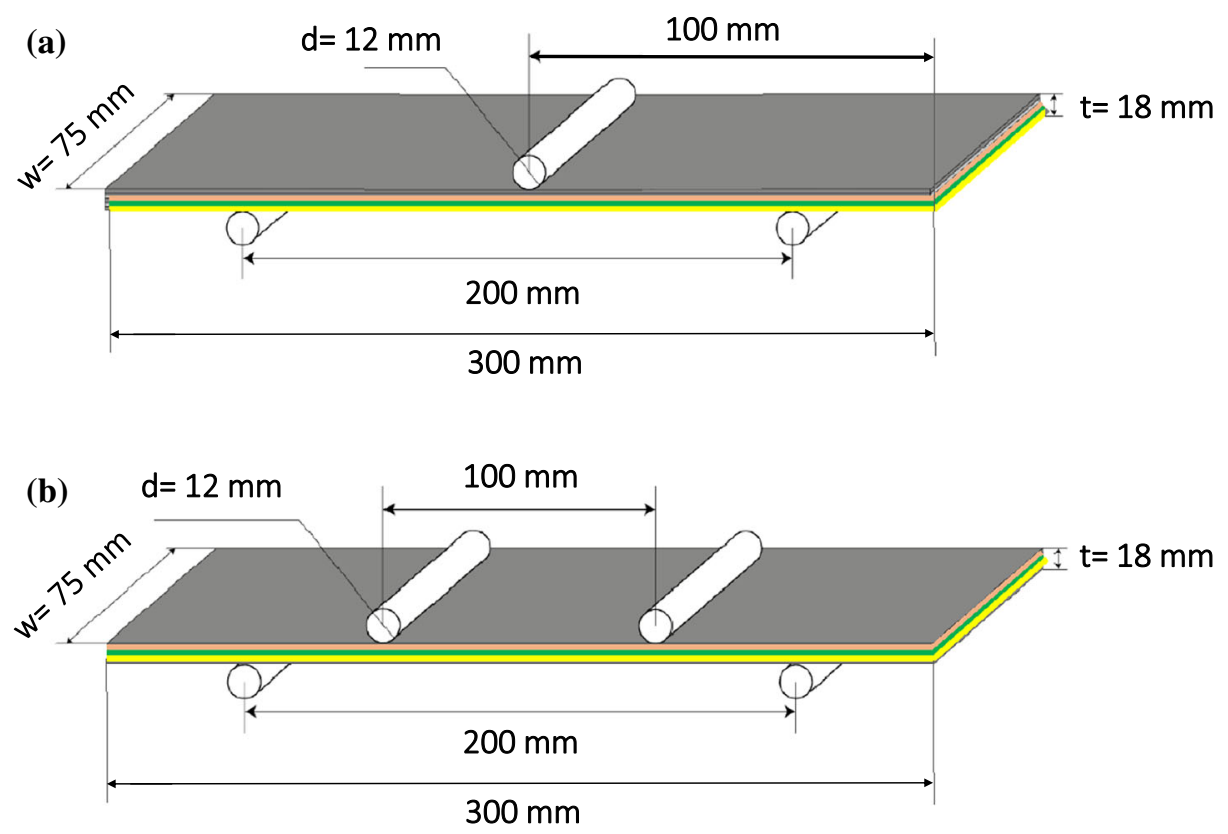

(c)

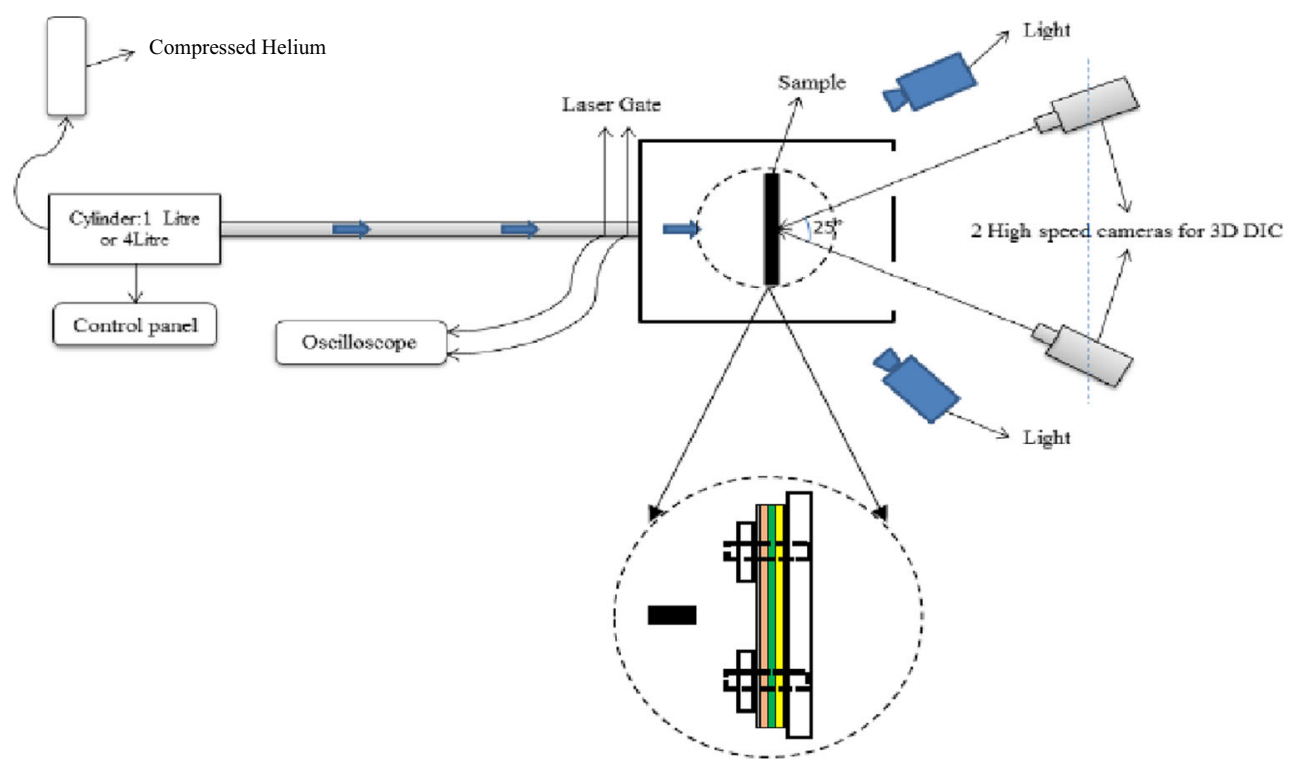

Figure 1 Schematic drawings of a the three-point bend test specimen and the loading rollers, $\mathbf{b}$ the four-point bend test specimen and the loading rollers, and $\mathrm{c}$ the gas-gun facility for high-velocity impact studies.

two cameras and a 3D analysis were also employed to validate the $2 \mathrm{D}$ approach. Measurements of the applied force were also taken at two second intervals, and therefore, the force data and the strain maps could be appropriately correlated. Three replicate tests were undertaken for all the sandwich structures that were studied.

For the impact studies, a gas-gun facility using compressed helium was employed to propel a projectile. The projectile intercepted two infrared (IR) sensors, $50 \mathrm{~mm}$ apart, at the end of the barrel. An oscilloscope received signals from the two sensors over time, which allowed the velocity of the projectile to be calculated. The target fixture was placed in a fully covered chamber with a thick metal and polymer shield. The projectile material employed was a high-density polyethylene (HDPE), to represent a compliant projectile. The projectile was flat-fronted 
and cylindrically shaped, and had a mass of $18.2 \mathrm{~g}$. High-speed cameras ('Phantom Miro M/R/LC310') were employed as shown in Fig. 1c to give the fullfield deformation. The set-up is similar to that described in detail by Kaboglu et al. [28]. The distance between the two high-speed cameras was $410 \mathrm{~mm}$ and the distance from the centre of the target to the camera was $925 \mathrm{~mm}$. This gave an angle of approximately $25^{\circ}$ between the two cameras, which is the recommended angle to perform stereo-vision measurements. The recording rate of the camera was 40,000 frames per second, and they were triggered simultaneously by the signal generated from the infrared sensors. A pair of identical 'Nikon' lenses, with a fixed focal length of $50 \mathrm{~mm}$, was used for both cameras. For the high-velocity gas-gun tests, where the projectile penetrated the specimen, the highspeed cameras were placed at the side of the chamber to measure the initial and residual velocities of the projectile.

\section{Results}

\section{Flexural test results}

The three-point and four-point bend flexural properties of the sandwich structures, with the five different configurations of the PVC foam core, were investigated (see Table 3). The deformation behaviour of the cores of the sandwich structures can be more readily compared by using normalised values of the measured compressive and shear strains. The measured values of the compressive and shear strains were, therefore, normalised with respect to the value of the corresponding yield strain of the appropriate foam core, as given in Table 1.

\section{The three-point bend flexural tests}

The various sandwich structures Figures 2, 3, 4, 5 and 6 show the force versus displacement traces from the three-point bend tests of the sandwich structures which were manufactured using the different configurations for the PVC foam core. Also, shown are the DIC maps of the normalised shear strain, $\hat{\varepsilon}_{x y}$, and the normalised through-thickness compressive strain, $\hat{\varepsilon}_{y}$, across the core of the sandwich structure. For each core configuration, these strains are mapped at different values of the displacement, as indicated on the force versus displacement trace. Also shown are photographs of the sandwich structure that illustrate the associated damage, which again are linked to values of the displacement as indicated on the force versus displacement trace.

The sandwich structure with a <80:80:80> layer foam core The force versus displacement curve given in Fig. 2 is for the $<80: 80: 80>$ sandwich structure and its response is elastic until just before 'Point 2 ' is reached on the force versus displacement trace. Up to this point, the strains measured from the DIC technique are relatively low and uniform throughout the core, and are well below the values of the compressive and shear yield strains. At 'Point 2' deviation from linear behaviour begins, which is accompanied by a very localised compression of the PVC foam core occurring, as is evident from the light-blue coloured regions corresponding to a value of $\hat{\varepsilon}_{y}$ of -0.5 under both the upper and lower rollers. At 'Point 3', which represents the maximum measured bending force, the value of $\hat{\varepsilon}_{y}$ under the rollers, particularly under the upper roller, exceeds a value of -1 . Thus, these $\hat{\varepsilon}_{y}$ strains are now plastic in nature. However, the values of $\hat{\varepsilon}_{x y}$ at 'Point 3' show that the shear strains in the core were still in the elastic range and uniformly distributed along the beam. The extent of core crushing under the upper roller increases after 'Point $3^{\prime}$ in the force versus displacement curve has been attained, with an increasingly large region developing in the core where the $\hat{\varepsilon}_{y}$ strain is plastic in nature. This results in a reduction in the measured bending force at 'Point 4'. In contrast, at 'Point 4' the shear strains, $\hat{\varepsilon}_{x y}$, are still uniformly distributed and, except for a very small region under the upper roller, are still below the value of the shear yield strain. At 'Point 5 ' on the force versus displacement trace, the relatively high compressive strains that are induced under the upper roller, and which are plastic in nature, lead to extensive core crushing, as shown in the photograph in Fig. 2. This significant core crushing under the upper roller has also led to a relatively high, but localised, deformation of the front, i.e. top, GFRP skin adjacent to this roller. This then causes the first layer of woven-glass fabric of this GFRP skin of the $<80: 80: 80>$ sandwich structure, whose direction is $0^{\circ}$ (i.e. along the length of the sandwich structure), to fracture at 'Point 6', as illustrated in Fig. 2. 
Figure 2 The three-point bend flexural test of the sandwich structure using three layers of PVC foam core with a configuration of $<80: 80: 80>$ : The force versus displacement trace, the strain maps (i.e. the normalised shear strain, $\hat{\varepsilon}_{x y}$, and normalised strain, $\hat{\varepsilon}_{y}$ ) of the core and photographs of the sandwich structure are shown. (The numbers against the strain maps and the photographs indicate whereabouts on the force versus displacement trace such information was obtained.) through-thickness compressive

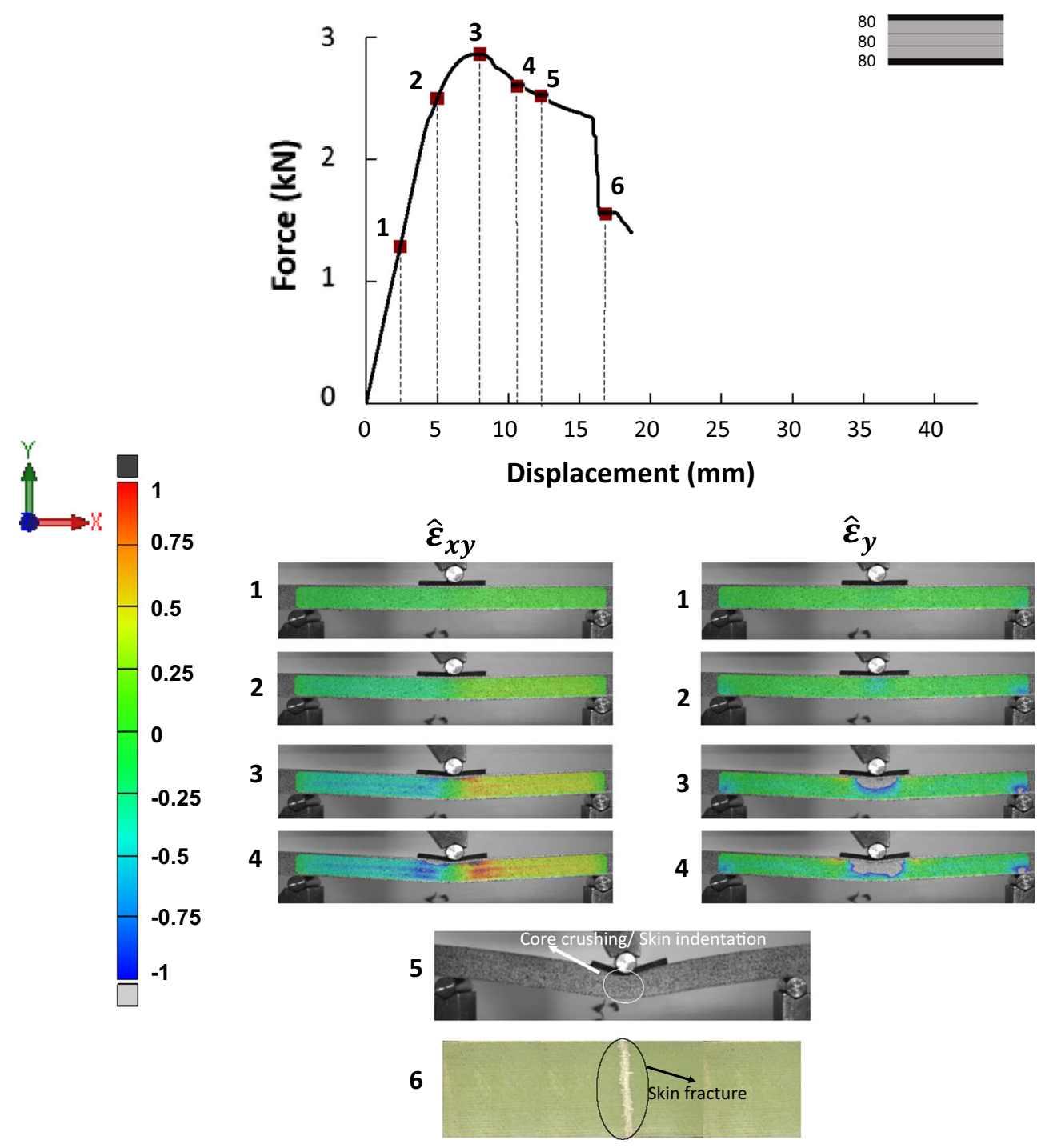

The sandwich structure with a <60:100:60> layer foam core In Fig. 3, for the $<60: 100: 60>$ core configuration for the sandwich structure, the normalised compressive and shear strains may be seen to be concentrated in the relatively low-density, outer, layers of the core. Significant compression of the core is apparent under the upper roller at a displacement as low as $2.5 \mathrm{~mm}$, i.e. at 'Point 1 '. Indeed, at 'Point 1 ' the value of $\hat{\varepsilon}_{y}$ under the upper roller exceeds a value of -1 in a relatively small localised region, and the compressive strain is, therefore, already plastic in nature. These effects arise because the foam layer with the relatively low-density is now adjacent to the front, i.e. top, GFRP skin. At 'Point 2' and 'Point 3' elastic shear strains also start to develop in both of the low-density, outer, layers. The relatively high values of $\hat{\varepsilon}_{y}$, and in an increasingly larger region of the upper foam layer of the core under the upper roller, are still a dominant feature; but again with only limited compression around the lower rollers being observed. At 'Point 4', deformation in the core has developed predominantly in the low-density, outer, core layers and is mainly confined to the centre of the beam. Indeed, the grey colorations reveal that the values of the shear strains in the core on the righthand side of the specimen are $\hat{\varepsilon}_{x y}>1$ and on the lefthand side are $\hat{\varepsilon}_{x y}>-1$. These shear strains are therefore plastic in nature. Further, at 'Point 4', significant compression of the core under the upper roller has occurred and a small region on the upper core layer, outside of the contact area, has gone into tension, with $\hat{\varepsilon}_{y}>1$. At this stage, it is evident that, compared to the $<80: 80: 80>$ sandwich structure, see Fig. 2, the maximum force-carrying capacity of the 


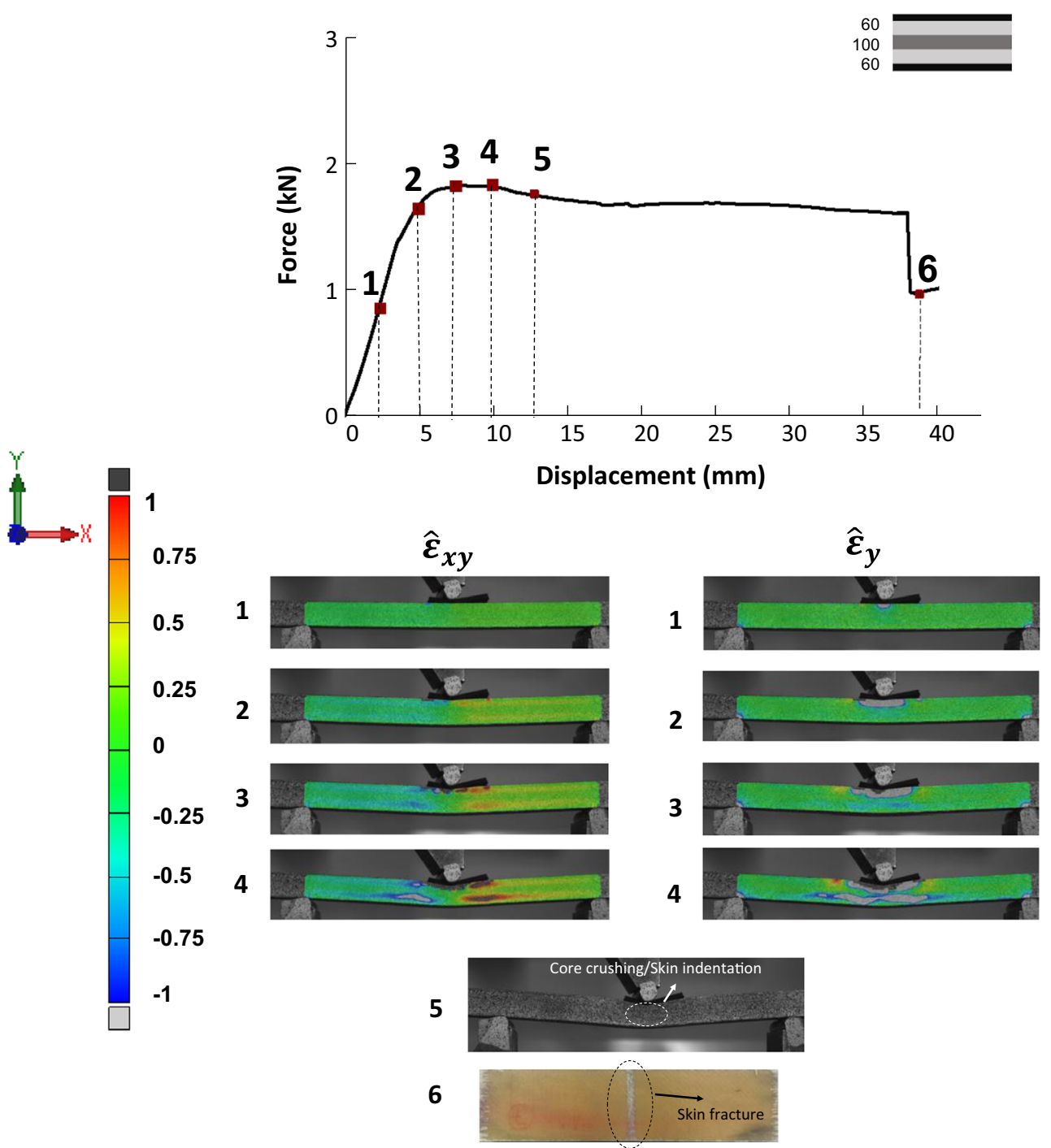

Figure 3 The three-point bend flexural test of the sandwich structure using three layers of PVC foam core with a configuration of $<60: 100: 60\rangle$ : The force versus displacement trace, the strain maps (i.e. the normalised shear strain, $\hat{\varepsilon}_{x y}$, and normalised through-

$<60: 100: 60>$ sandwich structure is reduced. The relatively high, and plastic, values of $\hat{\varepsilon}_{y}$ in the core of the $<60: 100: 60>$ sandwich structure under the upper roller leads to a relatively high, but localised, deformation of the front GFRP skin adjacent to this roller. Indeed, at 'Point 5', this has led to core crushing, which has resulted in an indentation of the GFRP skin having occurred. This then causes the first layer of this GFRP skin of the <60:100:60> sandwich structure, whose direction is $0^{\circ}$ (i.e. longitudinal), to fracture at 'Point $6^{\prime}$, again as illustrated in Fig. 3. However, the fracture of the front GFRP skin for the $<60: 100: 60>$ sandwich structure is delayed compared thickness compressive strain, $\hat{\varepsilon}_{y}$ ) of the core and photographs of the sandwich structure are shown. (The numbers against the strain maps and the photographs indicate whereabouts on the force versus displacement trace such information was obtained.).

to that of the $<80: 80: 80>$ sandwich structure, i.e. a displacement at failure of approximately $40 \mathrm{~mm}$ compared to $20 \mathrm{~mm}$, respectively, is recorded (see Figs. 3 and 2).

The sandwich structure with a $<100: 60: 100>$ layer foam core In Fig. 4, for the $<100: 60: 100>$ core configuration of the sandwich structure, the compressive and shear strains are concentrated in the low-density, middle, layer of the core. Elastic shear strains start to develop in this middle, low-density, layer at 'Point 2' and compressive strains are also seen to arise but are limited to small regions of the outer layers of the core 

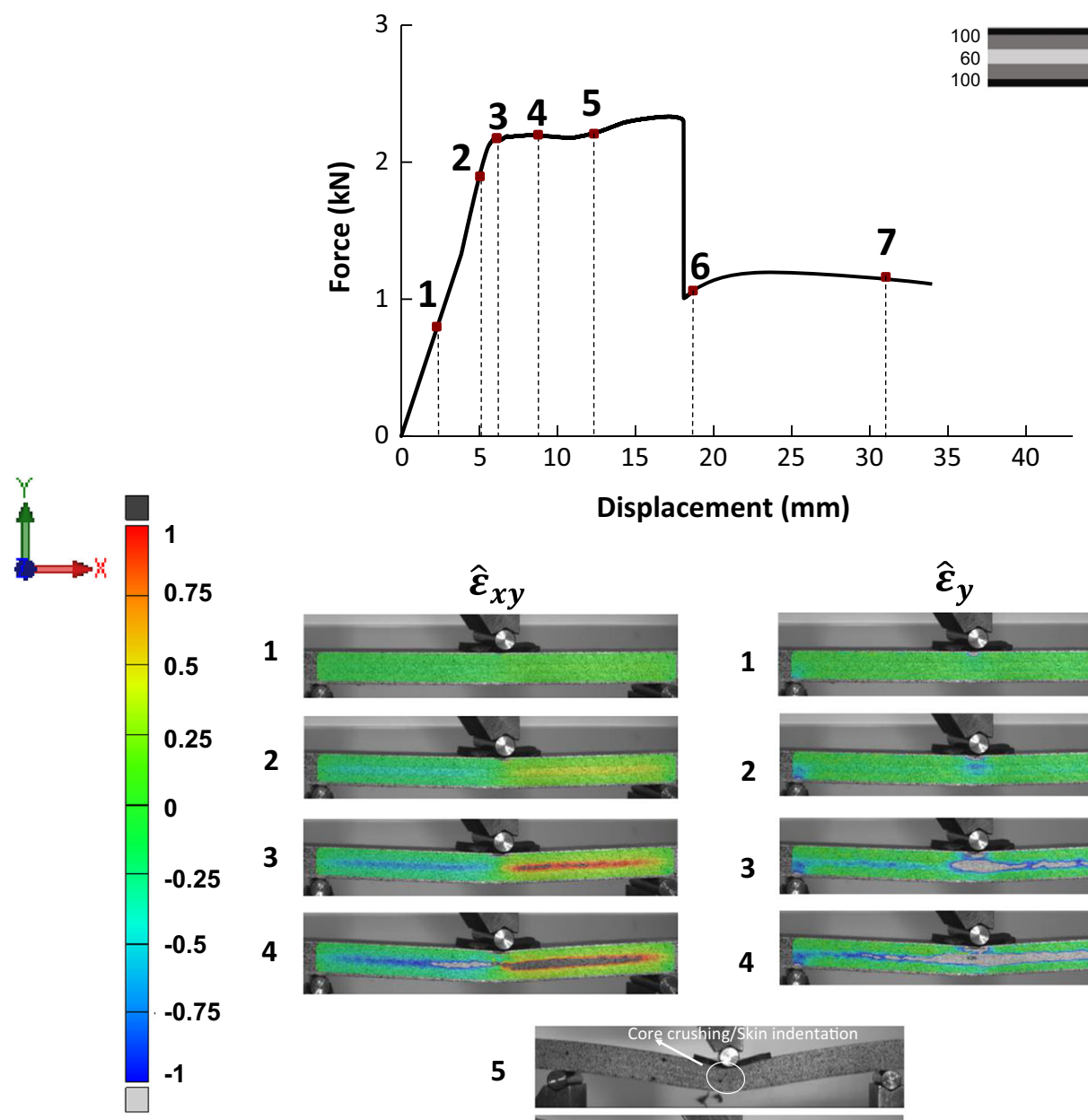

1

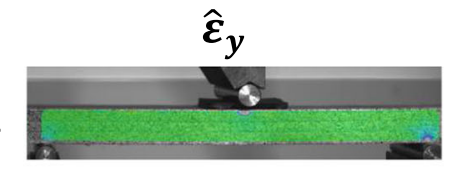

2

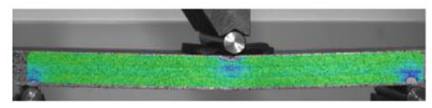

3

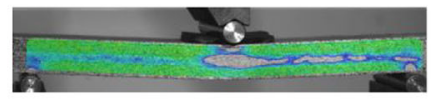

4
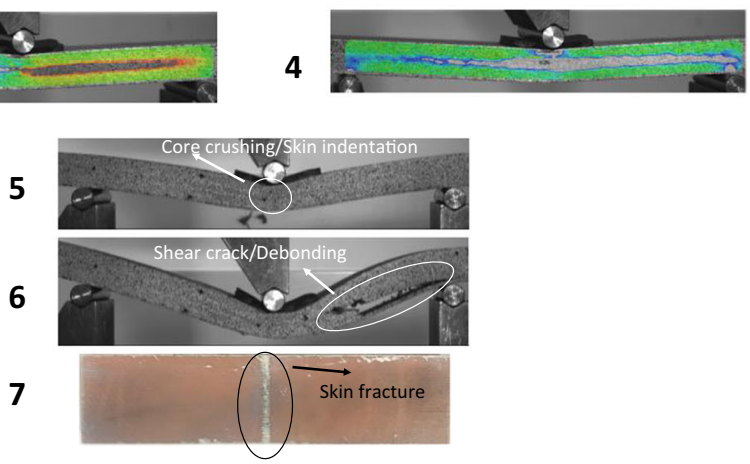

Figure 4 The three-point bend flexural test of the sandwich structure using three layers of PVC foam core with a configuration of $<100: 60: 100>$ : The force versus displacement trace, the strain maps (i.e. the normalised shear strain, $\hat{\varepsilon}_{x y}$, and normalised through-

directly under the rollers. The compressive strain values in the middle, low-density, core layer attain a value of $\hat{\varepsilon}_{y}>-1$ at 'Point 3 ', whilst the shear strains also reach values in the middle core layer of $\hat{\varepsilon}_{x y}>-1$ on the left-hand side and of $\hat{\varepsilon}_{x y}>-1$ on the righthand side. All of these values indicate that these strains are plastic in nature. After 'Point 3' has been reached, the applied force remains almost constant, whilst the strains in the middle layer become more uniformly distributed along the layer. The crushing of the low-density, middle, layer of the core of the sandwich structure enables the beam to sustain a thickness compressive strain, $\hat{\varepsilon}_{y}$ ) of the core and photographs of the sandwich structure are shown. (The numbers against the strain maps and the photographs indicate whereabouts on the force versus displacement trace such information was obtained.).

relatively large displacement before failure without any reduction in its force-carrying capacity. At 'Point 5 ' core crushing, which results in an indentation of the GFRP skin, occurs. Just before 'Point 6 ' a shear crack initiates in the low-density, middle, layer of the core which then leads to debonding of the lower core layer from the rear GFRP skin. These failure mechanisms result in a rapid decrease in the applied force, as seen at 'Point 6 '. Following the growth of the shear crack and the debonding of the core from the rear GFRP skin, a fracture of the front, i.e. top, GFRP skin occurs at 'Point 7'. 


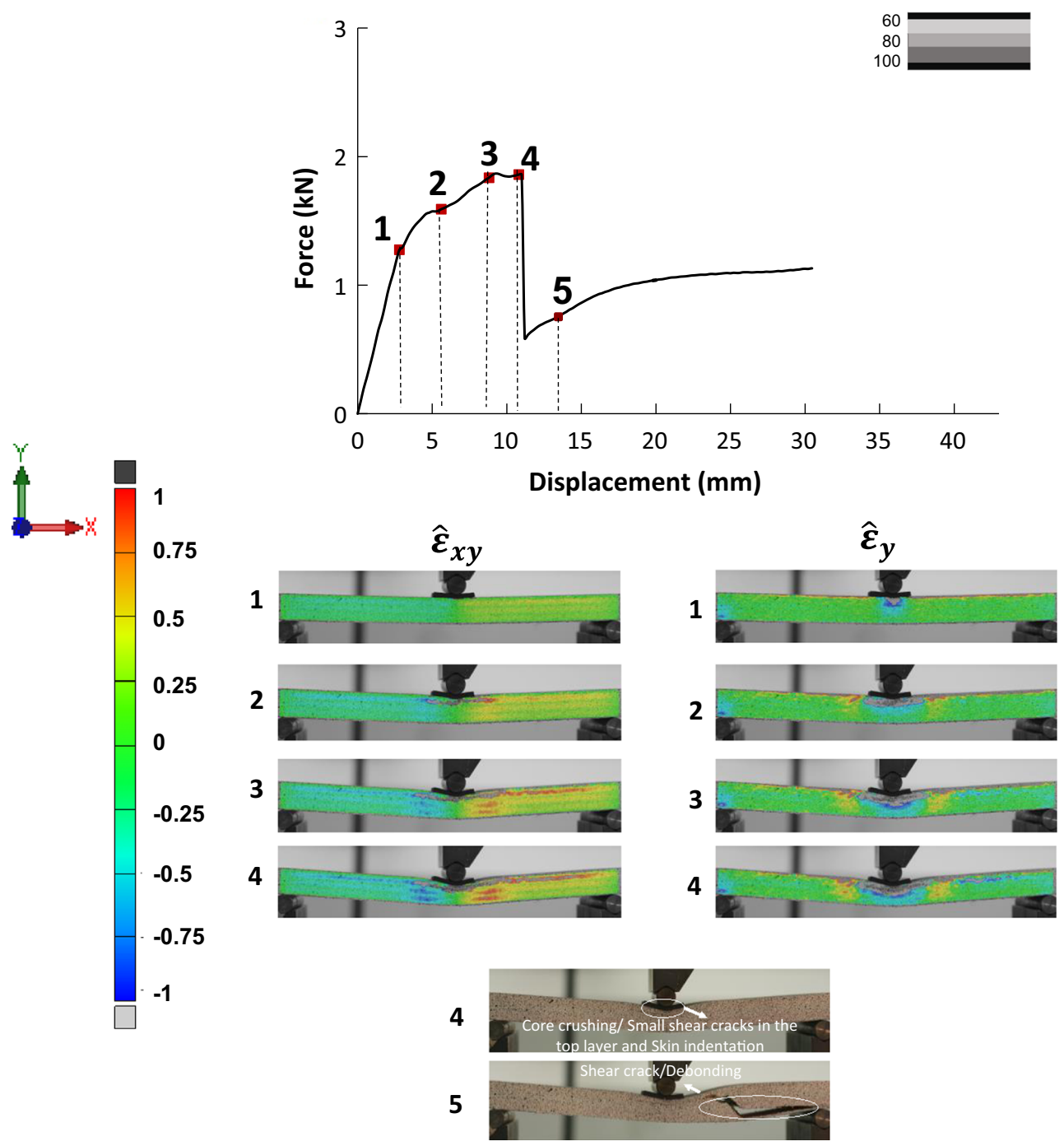

Figure 5 The three-point bend flexural test of the sandwich structure using three layers of PVC foam core with a configuration of $<60: 80: 100>$ : The force versus displacement trace, the strain maps (i.e. the normalised shear strain, $\hat{\varepsilon}_{x y}$, and normalised through-

The sandwich structure with a $<60: 80: 100>$ layer foam core For the $<60: 80: 100>$ core configuration of the sandwich structure, the results are shown in Fig. 5. It should be noted that the low-density layer of the core is adjacent to the upper loading roller and that the compressive and shear strains are concentrated in this low-density, upper, layer of the core. At 'Point 1', it may be seen that $\hat{\varepsilon}_{y}>-1$ in a small region of the low-density layer directly under the upper roller: so here plastic deformation of the core has already occurred. At 'Point 4', the low-density, upper, layer adjacent to the roller shows extensive regions under the upper roller where $\hat{\varepsilon}_{y}>-1$. Further, at 'Point $4^{\prime}$, the shear strains are also plastic in nature, i.e. $\hat{\varepsilon}_{x y}>-1$ thickness compressive strain, $\hat{\varepsilon}_{y}$ ) of the core and photographs of the sandwich structure are shown. (The numbers against the strain maps and the photographs indicate whereabouts on the force versus displacement trace such information was obtained.).

or $>-1$. These relatively high strain values lead to significant core crushing, shear cracking and skin/core debonding occurring, which cause a rapid and significant decrease in the applied force at 'Point 4', as may be seen in Fig. 5.

The sandwich structure with a $<100: 80: 60>$ layer foam core For the $<100: 80: 60>$ core configuration of the sandwich structure, the results are shown in Fig. 6. It should be noted that the high-density layer of the core is now adjacent to the upper loading roller, but that the compressive and shear strains are still concentrated in the low-density layer of the core, as was observed for the $<60: 80: 100>$ sandwich structure, see 


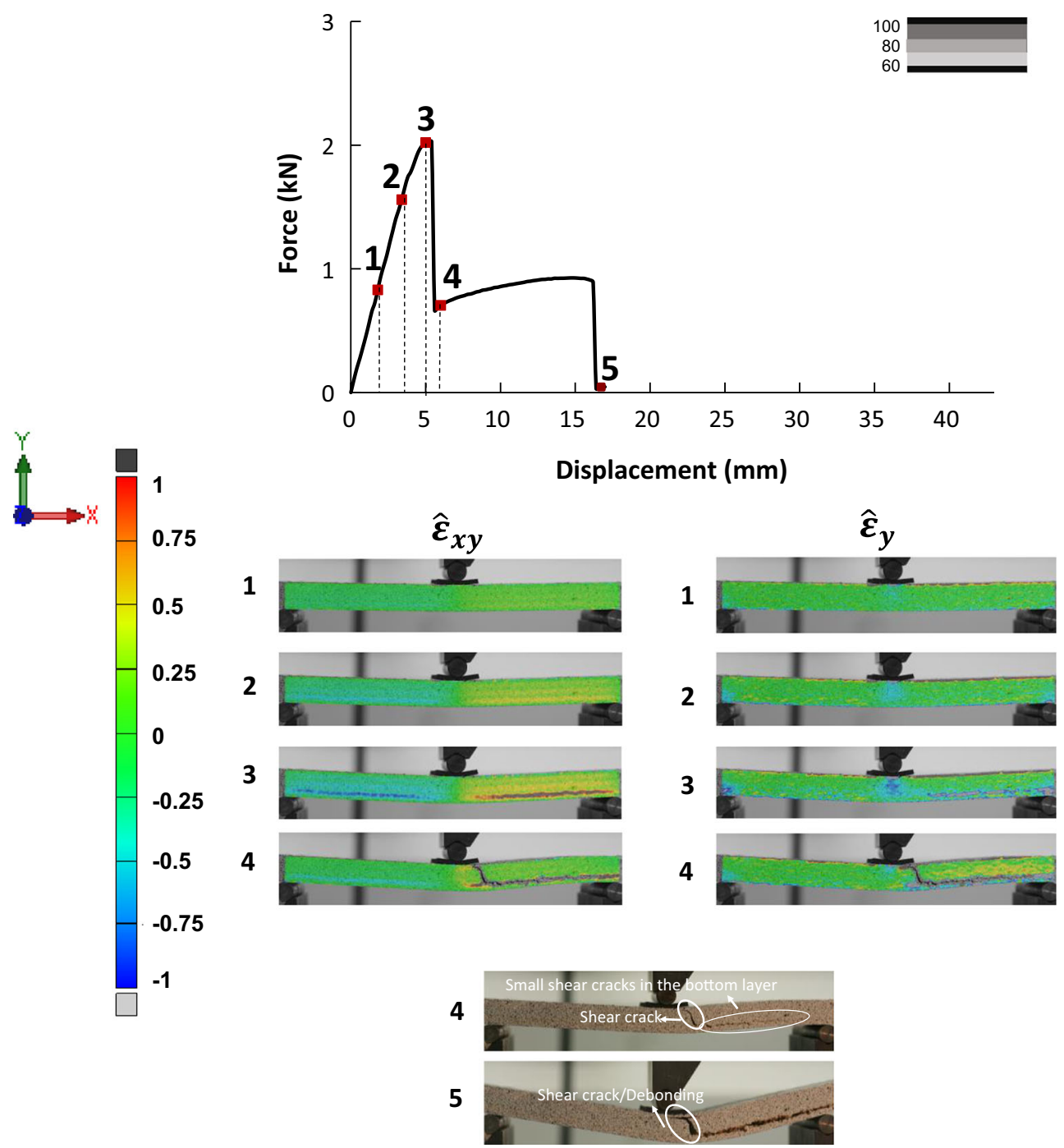

Figure 6 The three-point bend flexural test of the sandwich structure using three layers of PVC foam core with a configuration of $\langle 100: 80: 60\rangle$ : The force versus displacement trace, the strain maps (i.e. the normalised shear strain, $\hat{\varepsilon}_{x y}$, and normalised through-

Fig. 5. Until 'Point 3 ' on the force versus displacement trace in Fig. 6 is reached, the $<100: 80: 60>$ sandwich structure essentially exhibits linear-elastic behaviour. This observation is reflected in the values of $\hat{\varepsilon}_{y}$ and $\hat{\varepsilon}_{x y}$ being relatively low in value throughout the core. At 'Point 3', the values of these strains in the low-density, bottom, layer of the core indicate some plastic deformation in the core has been initiated. Just beyond 'Point 3 ' on the force versus displacement trace the force suddenly decreases. This was also observed for the $<60: 80: 100>$ configuration, see Fig. 5, and the displacement at which this occurs was significantly higher for the $<60: 80: 100>$ sandwich thickness compressive strain, $\hat{\varepsilon}_{y}$ ) of the core and photographs of the sandwich structure are shown. (The numbers against the strain maps and the photographs indicate whereabouts on the force versus displacement trace such information was obtained.).

structure. This sudden force decrease, at a relatively low displacement, just after 'Point 3' in Fig. 6 for the $<100: 80: 60>$ core configuration, is due to shear cracking and skin/core debonding associated with the low-density, bottom, foam layer. Just before 'Point $5^{\prime}$ in Fig. 6, these failure mechanisms have significantly grown in extent and lead to the total failure of the sandwich structure at a relatively low displacement.

Comparisons of the various configurations of sandwich structures under three-point bending Comparisons of the failure damage, for all the various core 
Table 4 Results of the three-point bend flexural tests for the various types of core configurations of the sandwich structures

\begin{tabular}{|c|c|c|c|c|c|c|}
\hline Configuration & $\begin{array}{l}\text { Initial } \\
\text { elastic } \\
\text { stiffness } \\
( \pm 30) \\
(\mathrm{N} / \mathrm{mm})\end{array}$ & $\begin{array}{l}\text { First } \\
\text { peak } \\
\text { force } \\
( \pm 50) \\
(\mathrm{N})\end{array}$ & $\begin{array}{l}\text { First peak } \\
\text { displacement } \\
( \pm 0.5) \\
(\mathrm{mm})\end{array}$ & $\begin{array}{l}\text { First force } \\
\text { drop } \\
\text { displacement } \\
( \pm 0.5) \\
(\mathrm{mm})\end{array}$ & $\begin{array}{l}\text { Energy } \\
\text { absorption } \\
\text { up to first } \\
\text { force drop } \\
( \pm 0.5) \\
\text { (J) }\end{array}$ & Type of failure \\
\hline$<80: 80: 80>$ & 530 & 2890 & 7.9 & 16.2 & 38.3 & Core crushing, moderate skin indentation, skin fracture \\
\hline$<60: 100: 60>$ & 470 & 1850 & 6.6 & 38.7 & 61.3 & Core crushing, extensive skin indentation, skin fracture \\
\hline$<100: 60: 100>$ & 520 & 2300 & 6.4 & 18.2 & 34.9 & $\begin{array}{l}\text { Core crushing, extensive skin indentation, skin fracture, } \\
\text { shear cracks, skin/core debonding }\end{array}$ \\
\hline$<60: 80: 100>$ & 460 & 1850 & 8.8 & 12.6 & 15.7 & $\begin{array}{l}\text { Core crushing, a few small cracks in the top layer and } \\
\text { skin indentation, shear cracks, skin/core debonding }\end{array}$ \\
\hline$<100: 80: 60>$ & 460 & 2100 & 5.4 & 6.3 & 6.7 & $\begin{array}{l}\text { Many small shear cracks in bottom layer, shear crack, } \\
\text { skin/core debonding }\end{array}$ \\
\hline
\end{tabular}

configurations of the sandwich structures, under three-point flexural bending are summarised in Table 4 . The main findings for the different configurations are given below:

- The initial elastic stiffness is very similar in value for all core configurations, since the average core densities of all the five configurations are very similar. The GFRP skin material, which is same for all the different core configurations, plays a significant role in the elastic part of the test.

- The <80:80:80> sandwich panel exhibits the highest first peak force.

- The <60:100:60> sandwich panel exhibits the highest energy absorption (i.e. $61.3 \mathrm{~J}$ ) up to the first load drop. This is because the two lowdensity outer layers offer protection by spreading the indentation load and suppressing the onset of shear cracking and skin/core debonding. However, although greater energy absorption is observed, there is a reduction in the maximum load that this configuration of sandwich structure, with the two low-density outer layers, can withstand in three-point loading.

- The displacements corresponding to the first force peak for all the configurations are very similar in value. The reason for that is that the yield strains of the different density foams are very similar in value.

- The values of the energy absorption up to the first force drop are higher for the symmetric core configurations (i.e. the $<80: 80: 80\rangle,<60: 100: 60\rangle$ and $<100: 60: 100>$ core configurations) compared with the non-symmetric configurations (i.e. the $<60: 80: 100>$ and $<100: 80: 60>$ core configurations). This is because the failure mechanisms of shear cracking, core crushing and skin/core debonding tend to occur more readily in the low-density foam layer when a non-symmetric configuration is employed. Further, these mechanisms are particularly likely to occur more readily in such configurations if the low-density layer is the bottom layer of the three layers that form the core. Since the low-density layer then provides a relatively easy fracture path for a shear crack to grow parallel to the rear GFRP skin and then easily cause debonding of this core layer from the skin.

\section{The four-point bend flexural tests}

The various sandwich structures Similar core configurations of sandwich structures tested under threepoint bend loading were also examined under fourpoint bend flexural loading. The strain visualisation from the four-point bend experiments is shown in Figs. 7, 8 and 9. The specific cases shown here are the $<80: 80: 80>$ core sandwich structure (Fig. 7), the $<60: 100: 60>$ core sandwich structure (Fig. 8) and the $<100: 80: 60>$ core sandwich structure (Fig. 9). (The force-displacement traces and associated failure 
Figure 7 The four-point bend flexural test of the sandwich structure using three layers of PVC foam core with a configuration of $<80: 80: 80>$ : The force versus displacement trace, the strain maps (i.e. the normalised shear strain, $\hat{\varepsilon}_{x y}$, and normalised throughthickness compressive strain, $\hat{\varepsilon}_{y}$ ) of the core and photographs of the sandwich structure are shown. (The numbers against the strain maps and the photographs indicate whereabouts on the force versus displacement trace such information was obtained.).
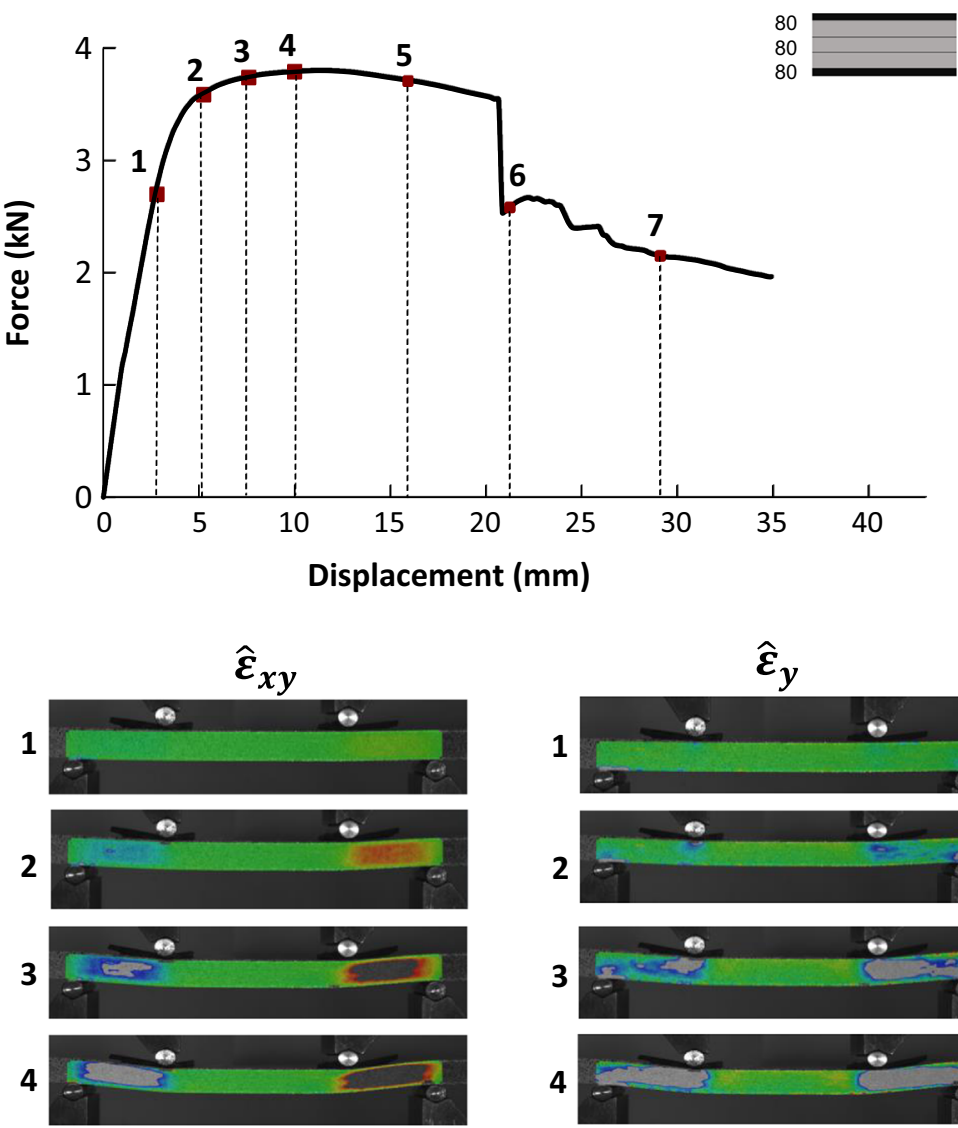

1
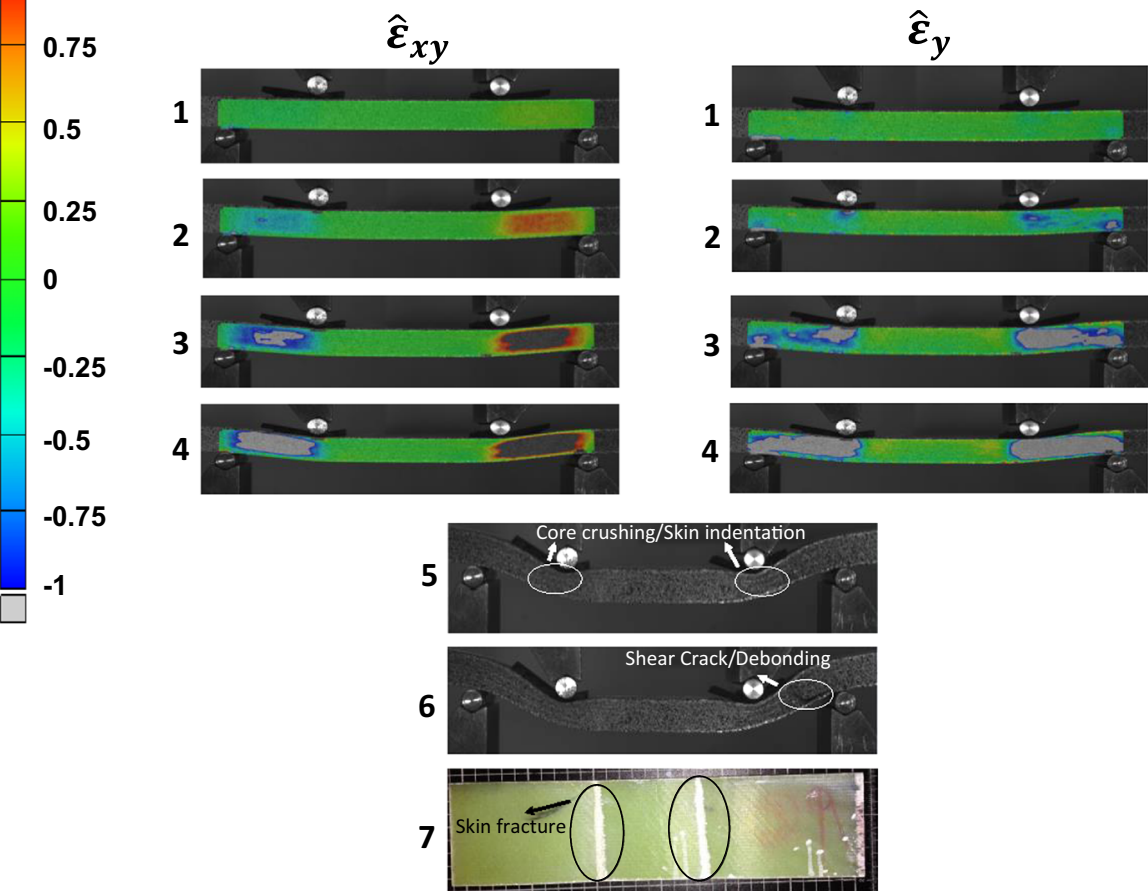

mechanisms of the $<100: 60: 100>$ core and the $<60: 80: 100>$ core sandwich structures under fourpoint bending were very similar to the behaviour of the $<60: 100: 60>$ core and <100:80:60> core sandwich structures, respectively, and hence, only details for the $<100: 60: 100>$ and $<60: 80: 100>$ core configurations are given.)

The sandwich structure with a $<80: 80: 80>$ layer foam core Figure 7 shows the results for the $<80: 80: 80>$ configuration and an elastic response is observed until 'Point 1 ' is reached. By 'Point 2', the compressive strains have exceeded their elastic limit under both the upper and lower rollers, as evidenced by the grey-coloured regions (i.e. $\hat{\varepsilon}_{y}=-1$ ). However, the values of the shear strains remain below their plastic values. As with the three-point bend tests, core crushing under the rollers occurs and is believed to be responsible for the deviation from the linear trend at 'Point 2'. At 'Point 3', both the compressive and shear strains have reached their plastic values, as indicated by the grey-coloured regions corresponding to plastic shear yielding on the right (i.e. $\hat{\varepsilon}_{x y}=1$ ) and on the left (i.e. $\hat{\varepsilon}_{x y}=-1$ ) of the upper rollers. The deformation in the central section of the beam remains uniform, with very small strains being observed in this region. Beyond 'Point 3', there is core crushing and skin indentation until the first force drop is observed soon after 'Pont 5' is reached. The 


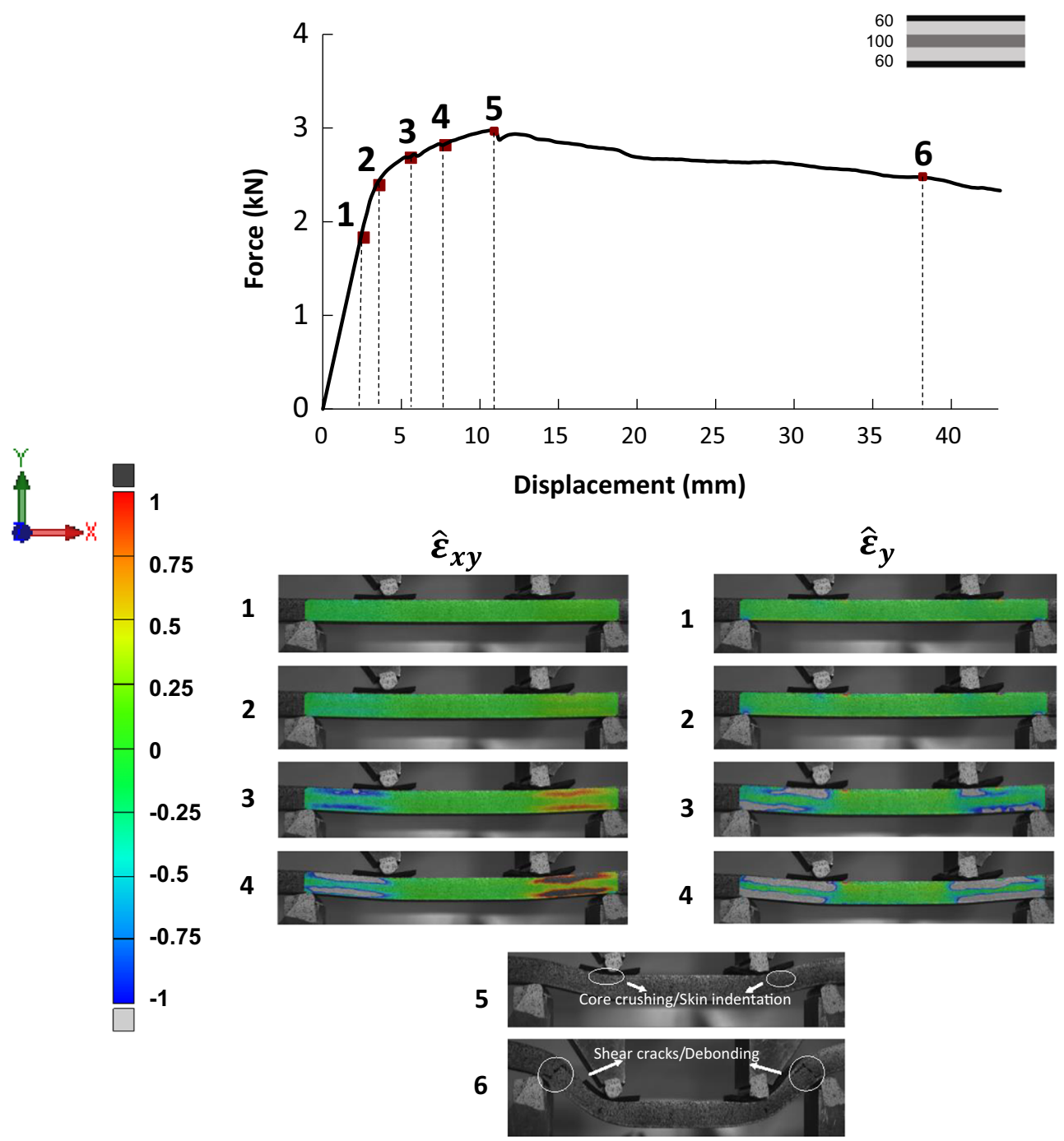

Figure 8 The four-point bend flexural test of the sandwich structure using three layers of PVC foam core with a configuration of $<60: 100: 60>$ : The force versus displacement trace, the strain maps (i.e. the normalised shear strain, $\hat{\varepsilon}_{x y}$, and normalised through-

force drop just before 'Point 6' occurs when shear cracking and skin/core debonding occur, as seen in Fig. 7. After 'Point 6', the front, i.e. top, GFRP skin starts to fracture. Indeed, at 'Point $7^{\prime}$ ', fracture of this GFRP skin can be clearly seen in Fig. 7 .

\section{The sandwich structures with $<60: 100: 60>$ and} $<100: 60: 100>$ layer foam cores In Fig. 8, with the $<60: 100: 60>$ symmetric core configuration, then core crushing, as shown by the grey-coloured regions at 'Point 3', started under all four rollers and soon extended to a large region of the low-density core layers, i.e. with values of $\hat{\varepsilon}_{y}=-1$. The shear strains also increased and by 'Point 4', grey-coloured thickness compressive strain, $\hat{\varepsilon}_{y}$ ) of the core and photographs of the sandwich structure are shown. (The numbers against the strain maps and the photographs indicate whereabouts on the force versus displacement trace such information was obtained.).

regions, corresponding to plastic shear yield, were visible on the right $\left(\hat{\varepsilon}_{x y}=1\right)$ and on the left $\left(\hat{\varepsilon}_{x y}=-1\right)$ of the upper rollers. At 'Point 5 ', core crushing and skin indentation can be seen in Fig. 8 . After 'Point 5', extensive shear cracking and skin/ core debonding develop under the upper rollers as the main failure mechanisms, as may be seen at 'Point $6^{\prime}$ in Fig. 8. As for the behaviour of the sandwich structure with a $<80: 80: 80>$ core configuration, the deformation in the central section of the beam remains uniform with very small strains being observed in between the central pair of upper rollers. 


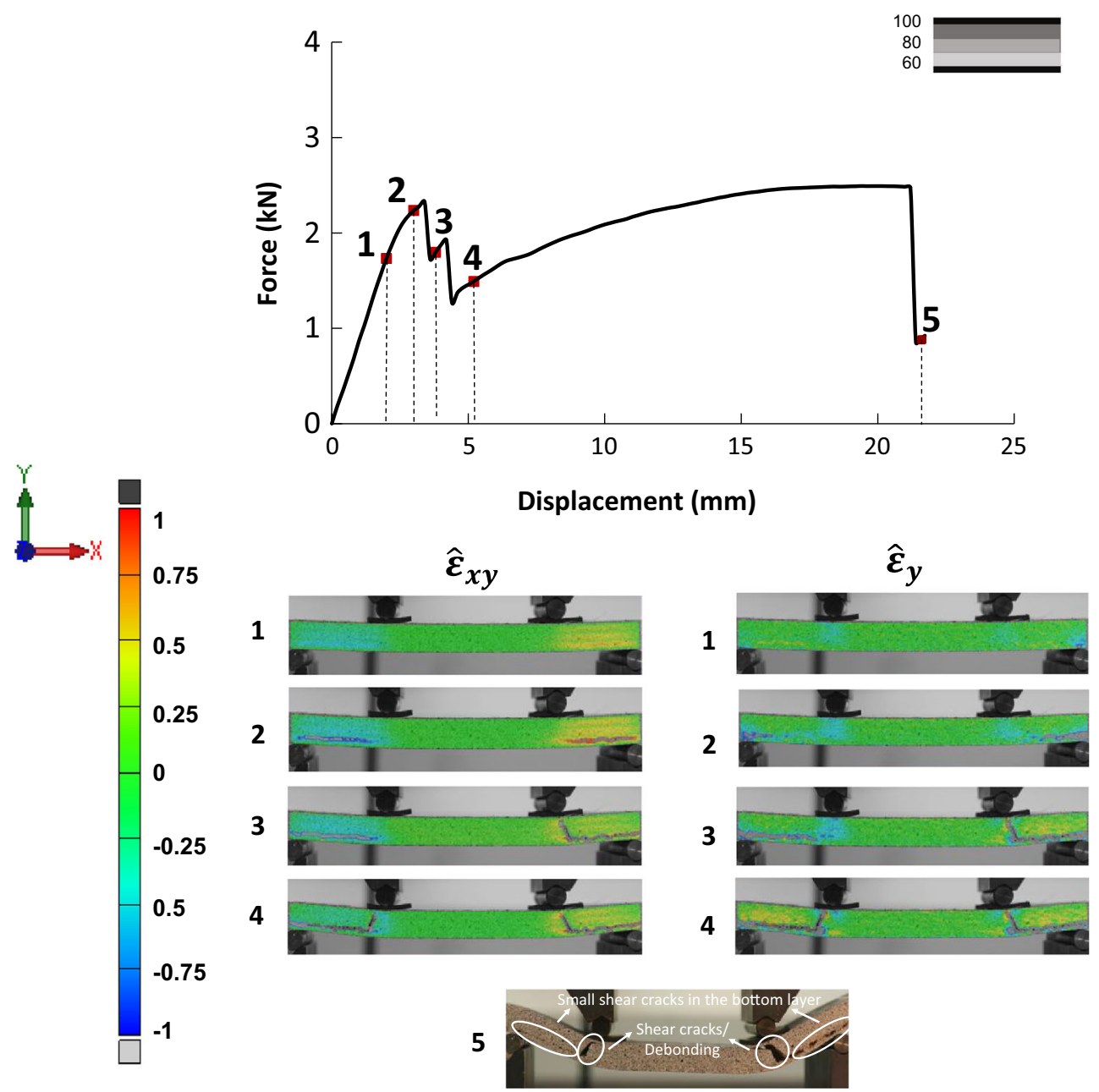

Figure 9 The four-point bend flexural test of the sandwich structure using three layers of PVC foam core with a configuration of $<100: 80: 60>$ : The force versus displacement trace, the strain maps (i.e. the normalised shear strain, $\hat{\varepsilon}_{x y}$, and normalised through-

For the $<100: 60: 100>$ symmetric core configuration under four-point bending, the deformation was mainly concentrated in the low-density layer, which was now the middle layer. The shear and compressive strains reached their plastic values at very similar force levels as for the $<60: 100: 60\rangle$ core configuration, Fig. 8. The force versus displacement trace for the $<100: 60: 100>$ symmetric core configuration was very similar to that for the $<60: 100: 60>$ symmetric core configuration, and the force remained relatively constant, without any significant force drop, up to a cross-head displacement of greater than $20 \mathrm{~mm}$. Thus, the low-density, middle, layer of the foam core dominated the deformation behaviour of the sandwich structure with the $<100: 60: 100>$ core thickness compressive strain, $\hat{\varepsilon}_{y}$ ) of the core and photographs of the sandwich structure are shown. (The numbers against the strain maps and the photographs indicate whereabouts on the force versus displacement trace such information was obtained.).

configuration, as observed for the three-point bend flexural tests.

The sandwich structures with <100:80:60> and $<60: 80: 100>$ layer foam cores In Fig. 9, the results for the sandwich structure with the $<100: 80: 60>$ core configuration are shown. The compressive and shear strains increase in the region between the upper and lower roller pairs. However, the sandwich structure did exhibit elastic behaviour up to 'Point 1 ' on the force versus displacement trace. The strains in the low-density, bottom, layer reach the compressive yield point (i.e. $\hat{\varepsilon}_{y}=-1$ ) and the shear yield point (i.e. $\hat{\varepsilon}_{x y}= \pm 1$ ) at 'Point 2 '. Shear cracking in the lowdensity, bottom, layer is clearly observed at 'Point 3', 
and more extensively at 'Point 4 '. Towards the end of the test a force drop was observed just before 'Point 5 ' which represents complete failure in the low-density, bottom, layer via shear cracking followed by skin/ core debonding.

The response of the sandwich structure with the $<60: 80: 100>$ core configuration was very similar to that for the $<100: 80: 60>$ core configuration, with failure initiating and developing in the low-density layer of the $<60: 80: 100>$ core configuration.

\section{Comparisons of the various configurations of sandwich} structures under four-point bending Table 5 shows a comparison of sandwich structures with the various core configurations under quasi-static four-point bend flexural loading. The main findings for the various configurations used for the sandwich structures and tested under four-point bending are given below:

- The values of the elastic stiffness of the sandwich structures using the various core configurations are very similar. This again reflects the fact that the average core densities of all the five configurations are very similar.

- The highest peak force and highest energy absorption, up to the first force drop, is recorded for the $<80: 80: 80>$ core configuration.
- The $<60: 100: 60>$ configuration of sandwich structure also performed very well with good energy absorption but, for this case of four-point flexural bend loading, there was no load drop. Therefore, it was not possible to give a definitive value of energy absorption up to the first load drop. However, from the results obtained, the indications are that it was improved in much the same way as for the case of three-point flexural bend loading.

- Sandwich structures with a symmetric core (i.e. $<80: 80: 80>,<60: 100: 60>$ and $<100: 60: 100>$ ) have a higher measured value for the first peak displacement than sandwich structures with a non-symmetric core configuration (i.e. the $<60: 80: 100>$ and the $<100: 80: 60>$ core configurations.)

- Sandwich structures with the $<100: 80: 60>$ and $<60: 80: 100>$ core configurations have the lowest energy absorption up to the point corresponding to the first force drop, compared to the other core configurations.

- Compared to three-point flexural bend loading, then generally four-point flexural loading removes the likelihood of indentation related failures. Also, as observed for the three-point bend loading tests, energy absorption was better for the symmetric core configurations than for the non-symmetric core configurations.

Table 5 Results of the four-point bend flexural tests for the various types of core configurations of the sandwich structures

\begin{tabular}{|c|c|c|c|c|c|c|}
\hline Configuration & $\begin{array}{l}\text { Initial elastic } \\
\text { stiffness } \\
\pm 40(\mathrm{~N} / \\
\mathrm{mm})\end{array}$ & $\begin{array}{l}\text { First } \\
\text { peak } \\
\text { force } \\
\pm 30(\mathrm{~N})\end{array}$ & $\begin{array}{l}\text { First peak } \\
\text { displacement } \\
\pm 0.5(\mathrm{~mm})\end{array}$ & $\begin{array}{l}\text { First force } \\
\text { drop } \\
\text { displacement } \\
\pm 0.5(\mathrm{~mm})\end{array}$ & $\begin{array}{l}\text { Energy } \\
\text { absorption up to } \\
\text { first force drop } \\
\pm 0.5(\mathrm{~J})\end{array}$ & Type of failure \\
\hline$<80: 80: 80>$ & 970 & 3790 & 12.8 & 20.9 & 74.8 & $\begin{array}{l}\text { Core crushing, extensive skin } \\
\text { indentation, skin fracture }\end{array}$ \\
\hline$<60: 100: 60>$ & 720 & 2990 & 11.0 & $-^{\mathrm{a}}$ & $-^{\mathrm{a}}$ & $\begin{array}{l}\text { Core crushing, moderate skin } \\
\text { indentation, shear cracks in the outer } \\
\text { layers, skin/core debonding }\end{array}$ \\
\hline$<100: 60: 100>$ & 980 & 3220 & 12.1 & $-^{\mathrm{a}}$ & $-^{\mathrm{a}}$ & $\begin{array}{l}\text { Core crushing, extensive skin } \\
\text { indentation, shear cracks in the } \\
\text { middle layer, skin/core debonding }\end{array}$ \\
\hline$<60: 80: 100>$ & 810 & 2210 & 4.0 & 4.4 & 6.6 & $\begin{array}{l}\text { Core crushing, extensive skin } \\
\text { indentation, shear cracks in the upper } \\
\text { layer, skin fracture, skin/core } \\
\text { debonding }\end{array}$ \\
\hline$<100: 80: 60>$ & 830 & 2340 & 4.2 & 4.7 & 6.8 & $\begin{array}{l}\text { Shear cracks in the bottom layer, } \\
\text { skin/core debonding }\end{array}$ \\
\hline
\end{tabular}

${ }^{a}$ There was no force drop observed for the $<100: 60: 100>$ and $<60: 100: 60>$ sandwich structures 


\section{High-velocity impact results}

For the various core configurations employed in the sandwich structures tests were performed at different velocities using the compliant projectile, and sectional views after impact were recorded. Figure 10 shows these sectional views for all the impacted sandwich structure configurations which were previously evaluated using three-point bend and fourpoint bend flexural loading. All the various core configurations, except for the $<60: 80: 100>$ core configuration, exhibit a perforation of the rear (i.e. nonimpacted) GFRP skin at the highest impact velocity of $230 \mathrm{~m} \mathrm{~s}^{-1}$, which gives a corresponding impact energy of $481 \mathrm{~J}$. Table 6 summarises all the high-velocity impact results for the various core configurations that were used for the sandwich structures.

From these results, the impact behaviour of the sandwich structure using the $<60: 80: 100>$ core configuration, where the low-density, upper, core layer was the first-impacted core layer, gave the best recorded performance. For this $<60: 80: 100>$ core configuration, Fig. 10 shows that the low-density layer is compressed, with partial debonding from the front skin, under a $178 \mathrm{~m} \mathrm{~s}^{-1}$ impact (which gives a corresponding impact energy of $288 \mathrm{~J}$ ). When the impact velocity was increased to $204 \mathrm{~m} \mathrm{~s}^{-1}$ (which gives a corresponding impact energy of $378 \mathrm{~J}$ ), the low-density core layer is further compressed and further debonded from the front GFRP skin that had been subjected to the impact from the projectile. More extensive debonding occurs at an impact velocity of $215 \mathrm{~m} \mathrm{~s}^{-1}$ (which gives a corresponding impact energy of $420 \mathrm{~J}$ ). However, even at the maximum impact velocity of $230 \mathrm{~m} \mathrm{~s}^{-1}$ (which gives a corresponding impact energy of $481 \mathrm{~J}$ ), no perforation of either GFRP skin is observed.

The sandwich structures with the $<60: 100: 60>$ and $<100: 60$ :100 $>$ core configurations did not show perforation of the rear skin up to an impact velocity of $215 \mathrm{~m} \mathrm{~s}^{-1}$ (which gives a corresponding impact energy of $420 \mathrm{~J}$ ), but their rear GFRP skins did

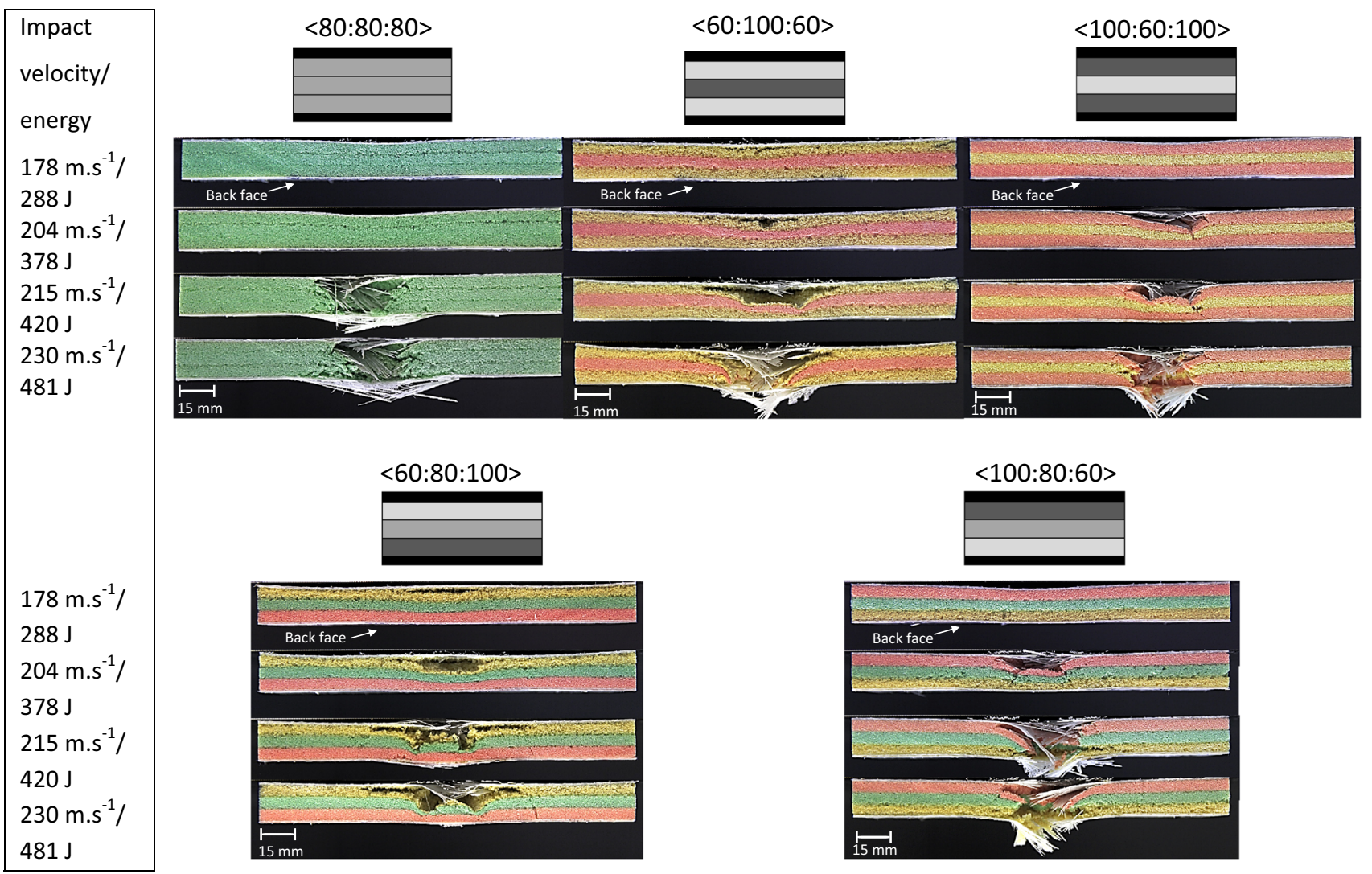

Figure 10 Sectional views for the $<80: 80: 80>,<60: 80: 100>$, $<100: 80: 60>,<60: 80: 100>$ and $<100: 80: 60>$ core configurations of the sandwich structures subjected to a high-velocity impact with a compliant projectile for different velocities and impact energies. (The projectile mass was 18.2 g.). 
perforate at $230 \mathrm{~m} \mathrm{~s}^{-1}$ (which gives a corresponding impact energy of $481 \mathrm{~J}$ ). From a visual assessment, Fig. 10 reveals that the sandwich structures using the $<80: 80: 80>$ and $<100: 80: 60>$ core configurations performed relatively poorly under the high-velocity impact testing with extensive damage and perforation of the rear GFRP skin being observed at $215 \mathrm{~m} \mathrm{~s}^{-1}$ (which gives a corresponding impact energy of $420 \mathrm{~J})$.

As noted above, the highest energy absorption and best penetration resistance under the high-velocity impact tests were found with the sandwich structure with the $<60: 80: 100>$ core configuration. The full DIC results for this sandwich structure are shown in Fig. 11 for an impact velocity of $230 \mathrm{~m} \mathrm{~s}^{-1}$, which gives a corresponding impact energy of $481 \mathrm{~J}$. Figure 11a and $b$ shows the out-of-plane displacement and the major principal strain, respectively, at the centre of the back face of the rear (i.e. non-impacted)
Figure 11 The full 3D DIC results for the sandwich structure with the $<60: 80: 100>$ core configuration for an impact velocity of $230 \mathrm{~m} \mathrm{~s}^{-1}$, which gives a corresponding impact energy of $481 \mathrm{~J}$ : $\mathbf{a}$ and $\mathbf{b}$ show the out-of-plane displacement and the major principal strain, respectively, at the centre of the back face of the rear (i.e. non-impacted) GFRP skin as a function of the time-scale of the impact event, and (c) shows the deformation profiles, across the middle section of the back face of the rear GFRP skin, at different time-scales.

GFRP skin as a function of the time-scale of the impact event. The maximum out-of-plane displacement and major principal strain at the centre of the back face of the rear GFRP skin of the sandwich structure are approximately $13 \mathrm{~mm}$ and 5.5\%, respectively, and occur at virtually the same time of impact loading. Figure 11c shows the deformation profiles, across the middle section of the back face of the rear GFRP skin, at different time-scales. These

Table 6 Results of the high-velocity impact tests for the various types of sandwich structures

\begin{tabular}{|c|c|c|c|}
\hline Core configuration & Velocity/energy of projectile & General observations & $\begin{array}{l}\text { Perforation of the } \\
\text { rear GFRP skin }\end{array}$ \\
\hline$<80: 80: 80>$ & $178 \mathrm{~m} \mathrm{~s}^{-1} / 288 \mathrm{~J}$ & Slight core crushing, slight skin indentation & No \\
\hline$<80: 80: 80>$ & $204 \mathrm{~m} \mathrm{~s}^{-1 / 378 \mathrm{~J}}$ & Core crushing, skin indentation & No \\
\hline$<80: 80: 80>$ & $215 \mathrm{~m} \mathrm{~s}^{-1} / 420 \mathrm{~J}$ & Shear cracks, fibre breakage on both skins & Yes \\
\hline$<80: 80: 80>$ & $230 \mathrm{~m} \mathrm{~s}^{-1} / 481 \mathrm{~J}$ & Shear cracks, fibre breakage on both skins & Yes \\
\hline$<60: 100: 60>$ & $178 \mathrm{~m} \mathrm{~s}^{-1} / 288 \mathrm{~J}$ & Core crushing, skin indentation & No \\
\hline$<60: 100: 60>$ & $204 \mathrm{~m} \mathrm{~s}^{-1 / 378 \mathrm{~J}}$ & Moderate core crushing, skin indentation & No \\
\hline$<60: 100: 60>$ & $215 \mathrm{~m} \mathrm{~s}^{-1} / 420 \mathrm{~J}$ & $\begin{array}{l}\text { Extensive core crushing, fibre breakage on impacted (i.e. } \\
\text { front) skin face }\end{array}$ & No \\
\hline$<60: 100: 60>$ & $230 \mathrm{~m} \mathrm{~s}^{-1} / 481 \mathrm{~J}$ & Core crushing, shear cracks, fibre breakage on both skins & Yes \\
\hline$<100: 60: 100>$ & $178 \mathrm{~m} \mathrm{~s}^{-1} / 288 \mathrm{~J}$ & Slight core crushing, slight skin indentation & No \\
\hline$<100: 60: 100>$ & $204 \mathrm{~m} \mathrm{~s}^{-1} / 378 \mathrm{~J}$ & $\begin{array}{l}\text { Moderate core crushing, shear cracks, fibre breakage on } \\
\text { impacted (i.e. front) skin face }\end{array}$ & No \\
\hline$<100: 60: 100>$ & $215 \mathrm{~m} \mathrm{~s}^{-1} / 420 \mathrm{~J}$ & $\begin{array}{l}\text { Moderate core crushing, shear cracks, fibre breakage on } \\
\text { impacted (i.e. front) skin face }\end{array}$ & No \\
\hline$<100: 60: 100>$ & $230 \mathrm{~m} \mathrm{~s}^{-1} / 481 \mathrm{~J}$ & Core crushing, shear cracks, fibre breakage on both skins & Yes \\
\hline$<60: 80: 100>$ & $178 \mathrm{~m} \mathrm{~s}^{-1} / 288 \mathrm{~J}$ & Slight core crushing, slight skin indentation & No \\
\hline$<60: 80: 100>$ & $204 \mathrm{~m} \mathrm{~s}^{-1} / 378 \mathrm{~J}$ & $\begin{array}{l}\text { Extensive core crushing, shear cracks, fibre breakage on } \\
\text { impacted (i.e. front) skin face }\end{array}$ & No \\
\hline$<60: 80: 100>$ & $215 \mathrm{~m} \mathrm{~s}^{-1} / 420 \mathrm{~J}$ & $\begin{array}{l}\text { Extensive core crushing, shear cracks, fibre breakage on } \\
\text { impacted (i.e. front) skin face }\end{array}$ & No \\
\hline$<60: 80: 100>$ & $230 \mathrm{~m} \mathrm{~s}^{-1} / 481 \mathrm{~J}$ & $\begin{array}{l}\text { Extensive core crushing, shear cracks, some very fibre } \\
\text { breakage on impacted (i.e. front) skin face }\end{array}$ & No \\
\hline$<100: 80: 60>$ & $178 \mathrm{~m} \mathrm{~s}^{-1} / 288 \mathrm{~J}$ & Slight core crushing, slight skin indentation & No \\
\hline$<100: 80: 60>$ & $204 \mathrm{~m} \mathrm{~s}^{-1} / 378 \mathrm{~J}$ & $\begin{array}{l}\text { Extensive core crushing, shear cracks, fibre breakage on } \\
\text { impacted (i.e. front) skin face }\end{array}$ & No \\
\hline$<100: 80: 60>$ & $215 \mathrm{~m} \mathrm{~s}^{-1} / 420 \mathrm{~J}$ & Core crushing, shear cracks, fibre breakage on both skins & Yes \\
\hline$<100: 80: 60>$ & $230 \mathrm{~m} \mathrm{~s}^{-1} / 481 \mathrm{~J}$ & Core crushing, shear cracks, fibre breakage on both skins & Yes \\
\hline
\end{tabular}


(a)

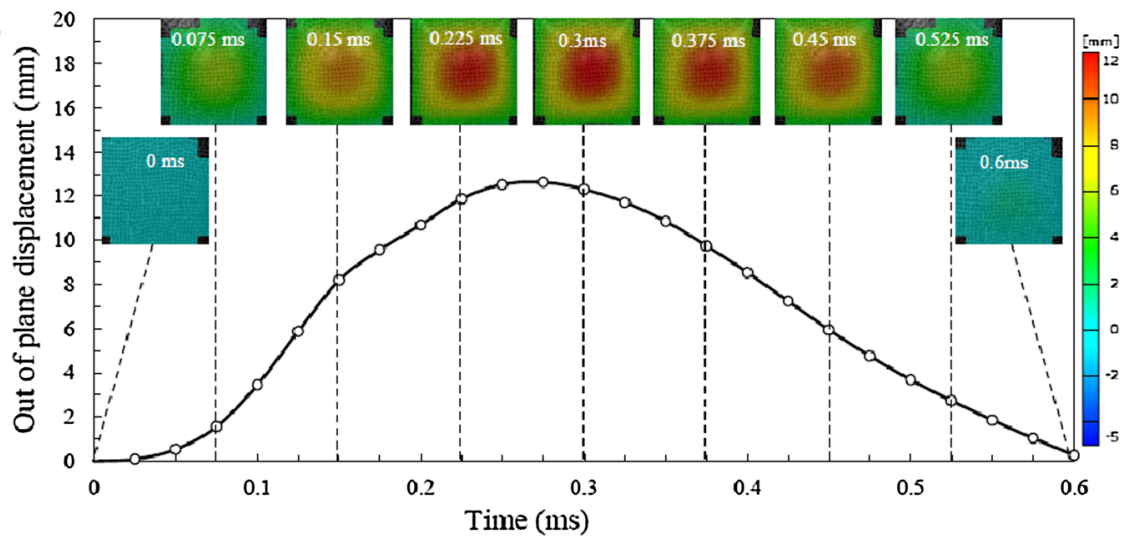

(b)

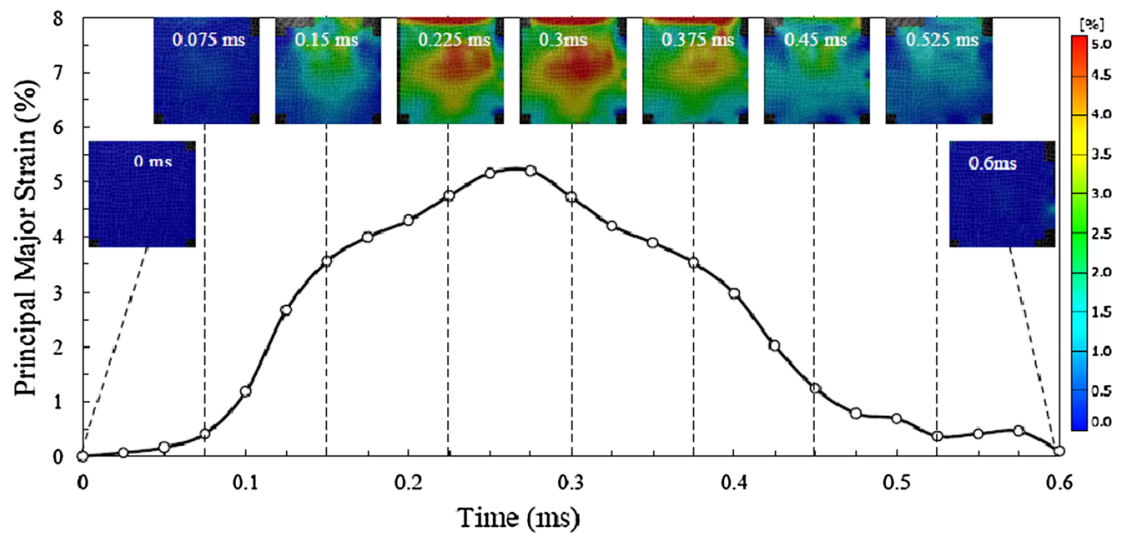

(c)

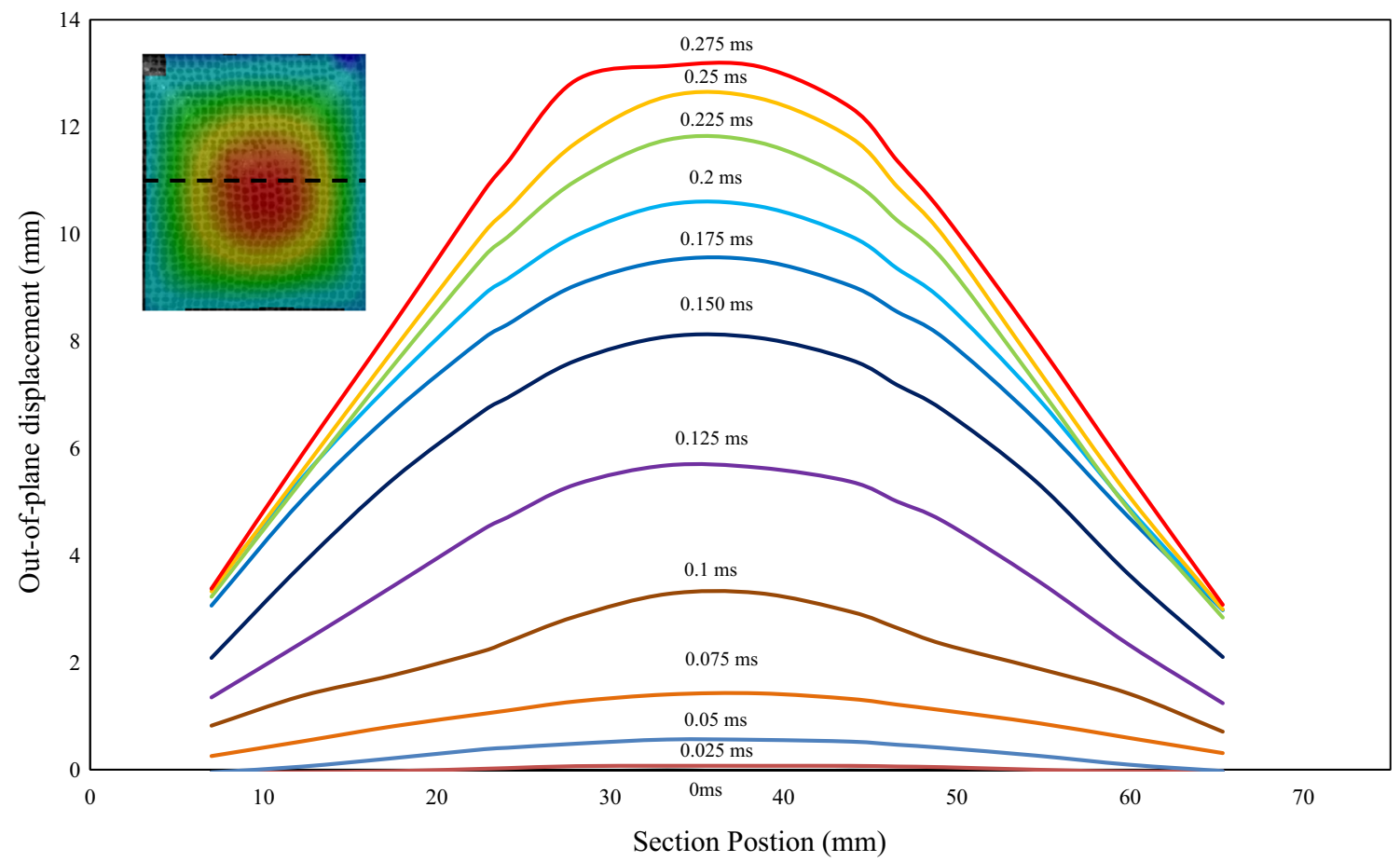


Figure 12 Comparison of the maximum out-of-plane displacement at the central point of the back face of the rear (i.e. non-impacted) GFRP skin for the different core configurations used for the sandwich structures: a at an impact velocity of $178 \mathrm{~m} \mathrm{~s}^{-1}$ and $\mathbf{b}$ at an impact velocity of $204 \mathrm{~m} \mathrm{~s}^{-1}$.
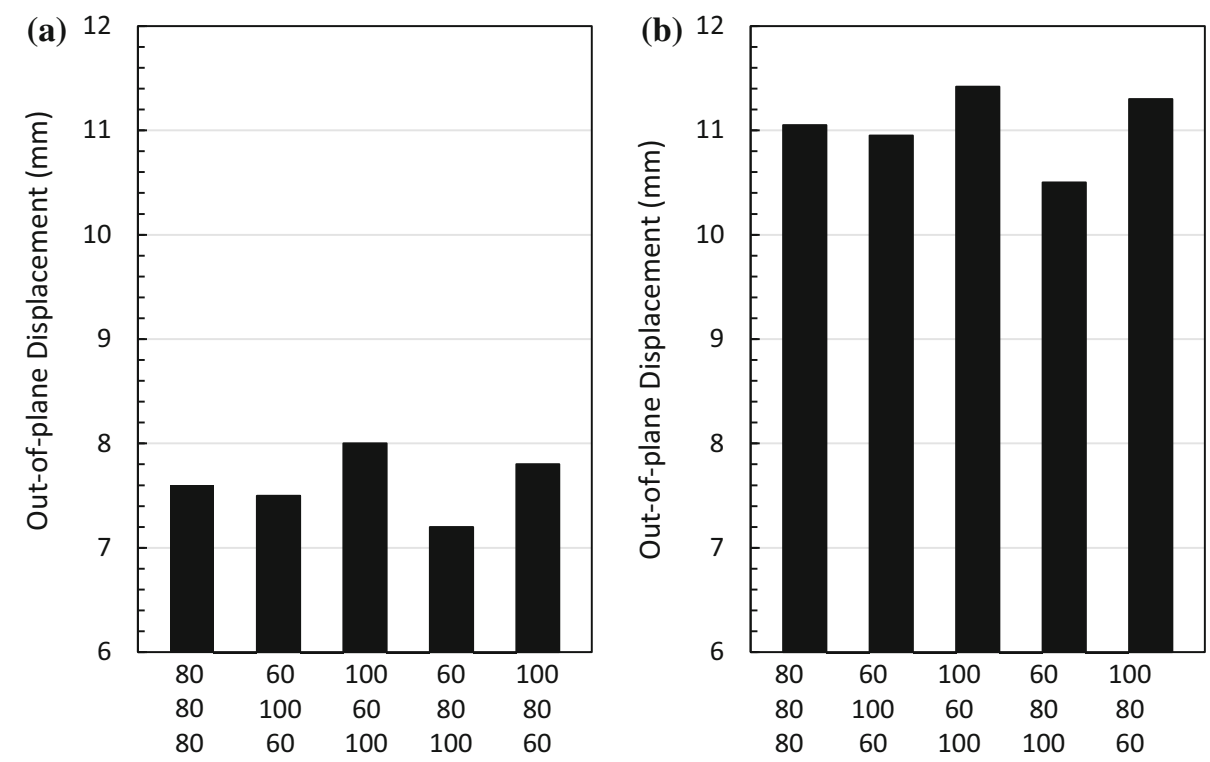

deformation profiles exhibit a near-symmetric deformation behaviour during the loading and unloading phases of the impact event, with the maximum displacement of about $13 \mathrm{~mm}$ of the back face of the rear GFRP skin.

In Fig. 12, the values of the maximum central outof-plane displacement are compared for the different core configurations used for the sandwich structures when subjected to two impact velocities of $178 \mathrm{~m} \mathrm{~s}^{-1}$ and $204 \mathrm{~m} \mathrm{~s}^{-1}$, both of which are below the velocities which cause perforation of the rear GFRP skin. The results reveal that, for the $<60: 80: 100\rangle$ core configuration, the value of the maximum out-of-plane displacement on the back face of the rear GFRP skin was relatively low. This clearly correlates with this core configuration giving the best impact performance of the various sandwich structures.

\section{Conclusions}

In the present study, various sandwich structures have been manufactured using glass-fibre-reinforcedpolymer (GFRP) skins but with different layers of poly(vinyl chloride) (PVC) foam as the core, with densities ranging from 60 to $100 \mathrm{~kg} / \mathrm{m}^{3}$. The effects of: (a) the density of the polymeric-foam core used and (b) grading the density of the foam core through its thickness on the quasi-static flexural properties and high-velocity impact behaviour of the sandwich structures have been investigated. The following are the main findings:
- The Digital Image Correlation (DIC) technique is very effective at delivering quantitative values of the deformation, strain and onset of damage for the quasi-static three-point bend and four-point bend flexural tests, and the high-velocity impact experiments.

- Under three-point and four-point bend loading, the use of the low-density core in the $<60: 100: 60>$ layered configuration reduces the likelihood of failure of the sandwich structure by a sudden force drop when compared with the uniform (i.e. homogeneous) $<80: 80: 80>$ layered core configuration.

- In the four-point flexural bending experiments, the sandwich structures exhibited a failure mechanism less dominated by an indentation failure of the GFRP skin but, instead, with shear cracking of the foam core of more importance, compared to the three-point flexural bending tests.

- The graded-density core sandwich structures, e.g. the <60:100:60> layered core configuration, fail under the quasi-static flexural bending tests through a relatively stable failure mechanism. Hence, they can typically withstand larger deflections before final failure than the sandwich structure with a uniform-density core, although at the cost of a decrease in flexural strength.

- When subjected to a high-velocity impact, the sandwich structure using the $<60: 80: 100>$ layered core configuration, with the low-density layer on the impacted side, results in the best impact performance, compared to all the other core 
configurations that were examined. This arises from a failure mechanism which involves compression occurring in the low-density core layer at an early stage which enables the sandwich structure to resist penetration by the impacting projectile.

- Thus, the overall conclusion from this research is that a symmetric graded-density configuration (e.g. the $<60: 100: 60>$ layered configuration) or a uniform core configuration (e.g. the $<80: 80: 80>$ layered configuration) gives the best performance for the sandwich structures when subjected to quasi-static flexural loading.

- However, when subjected to an impact by a compliant projectile travelling at a relatively highvelocity, there is an appreciable benefit in employing a graded-density $<60: 80: 100>$ core configuration for the sandwich structure, with the lowdensity foam layer of the graded core on the impacted side. Shukla et al. [29, 30] and Rolfe et al. [31] have also shown that a similar configuration of a graded core, with the lowest density on the front face, is beneficial for blast mitigation of composite sandwich structures. They found that in a blast situation the low-density core next to the impacted face-layer provides a cushion absorbing the incident blast wave.

- From testing the various core configurations that have been employed for the sandwich structures, there appears to be no correlation between the performance from the quasi-static three-point and four-point flexural bending tests of the various sandwich structures and the results from the impact tests. Thus, the high-velocity impact behaviour of such sandwich structures cannot be predicted from quasi-static flexural bending tests.

- These findings are very relevant for the testing and design of such sandwich structures which may experience high-velocity impact threats when employed, for example, as forward-facing components on aircraft, marine structures exposed to wave-slam loading and the leading edges of wind-turbine blades.

\section{Acknowledgements}

The authors are grateful to the Turkish Government for the PhD scholarship and to EDF Energy who supported Dr Cihan Kaboglu during his PhD studies, and to the First Aircraft Institute (FAI), through the Aviation Industry Corporation of China's (AVIC) Centre for Structural Design and Manufacture, for supporting Dr Long Yu during his PhD studies. The strong support from AVIC, First Aircraft Institute (FAI), Beijing Aeronautical Manufacturing Technology Research Institute (BAMTRI) and the Beijing Institute of Aeronautical Materials (BIAM) for Dr Iman Mohagheghian and Dr Cihan Kaboglu is also gratefully acknowledged.

Open Access This article is distributed under the terms of the Creative Commons Attribution 4.0 International License (http://creativecommons.org/ licenses/by/4.0/), which permits unrestricted use, distribution, and reproduction in any medium, provided you give appropriate credit to the original author(s) and the source, provide a link to the Creative Commons license, and indicate if changes were made.

\section{References}

[1] Nasirzadeh R, Sabet AR (2014) Study of foam density variations in composite sandwich panels under high velocity impact loading. Int J Impact Eng 63:129-139

[2] Rajaneesh A, Sridhar I, Rajendran S (2014) Relative performance of metal and polymeric foam sandwich plates under low velocity impact. Int J Impact Eng 65:126-136

[3] Ashwill TD, Paquette JA (2008) Composite materials for innovative wind turbine blades. In: SAMPE 2008, Los Angeles

[4] Mishnaevsky L Jr (2011) Composite materials in wind energy technology. In: Favorsky ON (ed) Thermal to mechanical energy conversion: engines and requirements. EOLSS Publishers, Oxford, UK

[5] Mølholt Jensen F, Branner K (2013) 1-Introduction to wind turbine blade design. In: Brøndsted P, Nijssen RPL (eds) Advances in wind turbine blade design and materials. Woodhead Publishing, UK, pp 3-28

[6] Chou J-S, Chiu C-K, Huang IK, Chi K-N (2013) Failure analysis of wind turbine blade under critical wind loads. Eng Fail Anal 27:99-118

[7] Marín JC, Barroso A, París F, Cañas J (2009) Study of fatigue damage in wind turbine blades. Eng Fail Anal 16(2):656-668

[8] Ackermann T (2012) Wind power in power systems, 2nd edn. Wiley, Hoboken 
[9] Steeves CA, Fleck NA (2004) Collapse mechanisms of sandwich beams with composite faces and a foam core, loaded in three-point bending. Part I: analytical models and minimum weight design. Int J Mech Sci 46(4):561-583

[10] Steeves CA, Fleck NA (2004) Collapse mechanisms of sandwich beams with composite faces and a foam core, loaded in three-point bending. Part II: experimental investigation and numerical modelling. Int $\mathrm{J}$ Mech Sci 46(4):585-608

[11] Abbadi A, Koutsawa Y, Carmasol A, Belouettar S, Azari Z (2009) Experimental and numerical characterization of honeycomb sandwich composite panels. Simul Model Pract Theory 17(10):1533-1547

[12] Juntikka R, Hallstrom S (2007) Shear characterization of sandwich core materials using four-point bending. J Sandwich Struct Mater 9(1):67-94

[13] Fathi A, Wolff-Fabris F, Altstädt V, Gätzi R (2013) An investigation on the flexural properties of balsa and polymer foam core sandwich structures: influence of core type and contour finishing options. J Sandwich Struct Mater 15(5):487-508

[14] Fathi A, Keller J-H, Altstaedt V (2015) Full-field shear analyses of sandwich core materials using Digital Image Correlation (DIC). Compos B Eng 70:156-166

[15] Kaboglu C, Pimenta S, Morris A, Dear JP (2017) The effect of different types of core material on th flexural behaviour of sandwich composites for wind turbine blades. J Therm Eng 3(2):1102-1109

[16] Battley M, Burman M (2010) Characterization of ductile core materials. J Sandwich Struct Mater 12(2):237-252

[17] Gupta N, Woldesenbet E (2005) Characterization of flexural properties of syntactic foam core sandwich composites and effect of density variation. J Compos Mater 39(24):2197-2212

[18] Gupta N, Woldesenbet E, Hore K, Sankaran S (2002) Response of syntactic foam core sandwich structured composites to three-point bending. J Sandwich Struct Mater 4(3):249-272

[19] Zhou G, Hill M, Hookham N (2007) Investigation of parameters governing the damage and energy absorption characteristics of honeycomb sandwich panels. J Sandwich Struct Mater 9(4):309-342
[20] Mines RAW, Worrall CM, Gibson AG (1998) Low velocity perforation beahviour of polymer composite sandwich panels. Int J Impact Eng 21(10):855-879

[21] Dear JP, Lee H, Brown SA (2005) Impact damage processes in composite sheet and sandwich honeycomb materials. Int $\mathrm{J}$ Impact Eng 32(1):130-154

[22] Dear JP, Brown SA (2003) Impact damage processes in reinforced polymeric materials. Compos A Appl Sci Manuf 34(5):411-420

[23] García-Castillo SK, Buitrago BL, Barbero E (2011) Behavior of sandwich structures and spaced plates subjected to high-velocity impacts. Polym Compos 32(2):290-296

[24] Razali N, Sultan M, Mustapha F, Yidris N, Ishak M (2014) Impact damage on composite structures-a review. Int J Eng Sci 3(7):08-20

[25] Data Sheet AIREX C70 Universal Structural Foam (2011) [cited December 2014; http://www.3accorematerials.com/ products/airex/airexreg-c70.html

[26] Zhou J, Hassan MZ, Guan Z, Cantwell WJ (2012) The low velocity impact response of foam-based sandwich panels. Compos Sci Technol 72(14):1781-1790

[27] ASTM C393 (2000) Standard test method for flexural properties of sandwich constructions. ASTM International, Philadelphia

[28] Kaboglu C, Mohagheghian I, Zhou J, Guan Z, Cantwell W, John S, Blackman BRK, Kinloch AJ, Dear JP (2018) Highvelocity impact deformation and perforation of fibre metal laminates. J Mater Sci 53(6):4209-4228. https://doi.org/10. 1007/s10853-017-1871-2

[29] Wang E, Gardner N, Shukla A (2009) The blast resistance of sandwich composites with stepwise graded cores. Int J Solids Struct 46(18-19):3492-3502

[30] Gardner N, Wang E, Shukla A (2012) Performance of functionally graded sandwich composite beams under shock wave loading. Compos Struct 94(5):1755-1770

[31] Rolfe E, Kelly M, Arora H, Hooper PA, Dear JP (2017) Failure analysis using X-ray computed tomography of composite sandwich panels subjected to full-scale blast loading. Compos B Eng 129:26-40 